Article

\title{
Steric Quenching of Mn(III) Thermal Spin Crossover: Dilution of Spin Centers in Immobilized Solutions
}

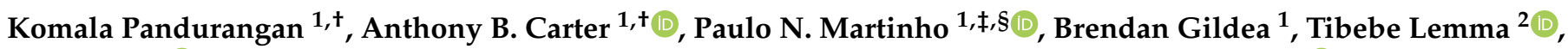 \\ Shang Shi ${ }^{1} \mathbb{1}$, Aizuddin Sultan ${ }^{1}$, Tia E. Keyes ${ }^{2}$, Helge Müller-Bunz ${ }^{1}$ and Grace G. Morgan ${ }^{1, * \mathbb{C}}$ \\ 1 School of Chemistry, University College Dublin (UCD), Belfield, D04 V1W8 Dublin, Ireland; \\ komalaj@gmail.com (K.P.); anthony.carter@ucd.ie (A.B.C.); pnmartinho@fc.ul.pt (P.N.M.); \\ brendan.gildea@novartis.com (B.G.); shang.shi@ucdconnect.ie (S.S.); aizuddin.sultan@ucdconnect.ie (A.S.); \\ helge.muellerbunz@ucd.ie (H.M.-B.) \\ 2 School of Chemical Sciences, Dublin City University, D09 Y5N0 Dublin, Ireland; tlemma@gmail.com (T.L.); \\ tia.keyes@dcu.ie (T.E.K.) \\ * Correspondence: grace.morgan@ucd.ie \\ + These authors contributed equally to this work. \\ $\ddagger \quad$ Present Address: Biosystems and Integrative Sciences Institute (BioISI), Faculdade de Ciências, Universidade \\ de Lisboa, Campo Grande, 1749-016 Lisboa, Portugal. \\ $\S$ Present Address: Centro de Química Estrutural, Faculdade de Ciências, Universidade de Lisboa, Campo \\ Grande, 1749-016 Lisboa, Portugal.
}

\section{check for}

updates

Citation: Pandurangan, K.; Carter,

A.B.; Martinho, P.N.; Gildea, B.;

Lemma, T.; Shi, S.; Sultan, A.; Keyes, T.E.; Müller-Bunz, H.; Morgan, G.G. Steric Quenching of Mn(III) Thermal Spin Crossover: Dilution of Spin

Centers in Immobilized Solutions.

Magnetochemistry 2022, 8, 8

https://doi.org/10.3390/

magnetochemistry 8010008

Academic Editor: Zoi G. Lada

Received: 1 December 2021

Accepted: 4 January 2022

Published: 10 January 2022

Publisher's Note: MDPI stays neutral with regard to jurisdictional claims in published maps and institutional affiliations.

Copyright: (C) 2022 by the authors. Licensee MDPI, Basel, Switzerland. This article is an open access article distributed under the terms and conditions of the Creative Commons Attribution (CC BY) license (https:// creativecommons.org/licenses/by/ $4.0 /)$
Abstract: Structural and magnetic properties of a new spin crossover complex [Mn(4,6-diOMesal 2323$)]^{+}$in lattices with $\mathrm{ClO}_{4}{ }^{-},(1), \mathrm{NO}_{3}^{-},(2), \mathrm{BF}_{4}{ }^{-},(3), \mathrm{CF}_{3} \mathrm{SO}_{3}{ }^{-}$, (4), and $\mathrm{Cl}^{-}$(5) counterions are reported. Comparison with the magnetostructural properties of the $\mathrm{C}_{6}, \mathrm{C}_{12}, \mathrm{C}_{18}$ and $\mathrm{C}_{22}$ alkylated analogues of the $\mathrm{ClO}_{4}{ }^{-}$salt of $\left[\mathrm{Mn}\left(4,6-\mathrm{diOMe}_{-} \mathrm{sal}_{2} 323\right)\right]^{+}$demonstrates that alkylation effectively switches off the thermal spin crossover pathway and the amphiphilic complexes are all high spin. The spin crossover quenching in the amphiphiles is further probed by magnetic, structural and Raman spectroscopic studies of the $\mathrm{PF}_{6}{ }^{-}$salts of the $\mathrm{C}_{6}, \mathrm{C}_{12}$ and $\mathrm{C}_{18}$ complexes of a related complex $\left[\mathrm{Mn}\left(3-\mathrm{OMe}-\mathrm{sal}_{2} 323\right)\right]^{+}$which confirm a preference for the high spin state in all cases. Structural analysis is used to rationalize the choice of the spin quintet form in the seven amphiphilic complexes and to highlight the non-accessibility of the smaller spin triplet form of the ion more generally in dilute environments. We suggest that lattice pressure is a requirement to stabilize the spin triplet form of $\mathrm{Mn}^{3+}$ as the low spin form is not known to exist in solution.

Keywords: spin crossover; Schiff-base; $\mathrm{Mn}^{3+}$; hexadentate; Jahn-Teller; crystal engineering

\section{Introduction}

Cooperative effects in spin crossover complexes are well-known to influence thermal evolution profile and many approaches to modulate a spin transition from gradual to abrupt have been reported. These include targeted crystal engineering through the inclusion of specific anions, guest molecules or ligand substituents [1-6] with 6-coordinate complexes of $\mathrm{Mn}(\mathrm{III})$ [4,7-12], $\mathrm{Fe}$ (III) [13-16], $\mathrm{Fe}(\mathrm{II})$ [17-25], and $\mathrm{Co}(\mathrm{II})$ [26-29], i.e., the full range of $d^{4}-d^{7}$ configurations for which thermal spin state switching is possible. Intermolecular interactions such as hydrogen-bonding [30-32] and $\pi-\pi$ stacking [33-37] have proven to be very effective mechanisms to connect $\mathrm{SCO}$-active sites in crystalline samples, as thermal differences in the intermolecular interaction can change the internal lattice pressure across a temperature gradient.

In parallel with classical crystal engineering studies, a significant body of work has emerged on the properties of amphiphilic SCO complexes both in the solid state and in soft media. Amphiphilicity can be conferred relatively easily by addition of long-chain alkyl groups to a polydentate ligand and has been widely reported in Fe(II) SCO systems [38-53] and to a lesser extent in Fe(III) [54-63] and Co(II) [64]. Preparation of amphiphilic SCO 
complexes has been largely motivated by interest in surface properties, particularly in the preparation of spin-switchable Langmuir-Blodgett (LB) films for transfer as monolayers to a variety of substrates. However, the versatility of amphiphilic complexes means that their properties have also been investigated in media other than LB films. These include studies into solution properties of micelles and inverse micelles [54-60,64-68], investigation into the efficacy of using amphiphiles in formation of templated SCO nanowires [61] or thermally ordered metallomesogens [63]. Iron SCO systems, whether they are $+\mathrm{II}$ or $+\mathrm{III}$, have responded well to derivatization as amphiphiles and SCO is usually observed to persist, and in some cases to become more abrupt, on moving from the parent compound to the amphiphilic derivative. Studies on amphiphilic Mn(III) complexes are rare with only one report to date on the effect on the SCO profile of adding alkyl chains [64]. Here we report a new cationic Mn(III) SCO complex [Mn(4,6-diOMe-sal 2323$)]^{+}$and relate the thermal SCO observed in lattices with four different counterions to the structural properties at $100 \mathrm{~K}$. Attempts to prepare SCO alkylated derivatives of [Mn(4,6-diOMe-sal 2323$)]^{+}$ with $\mathrm{C}_{6}, \mathrm{C}_{12}, \mathrm{C}_{18}$ and $\mathrm{C}_{22}$ chains yielded only high spin (HS) complexes in contrast to the thermal SCO observed in the non-alkylated analogues. The challenges in retaining the SCO functionality in $\mathrm{Mn}(\mathrm{III})$ amphiphiles were underscored by investigation of the $\mathrm{C}_{6}, \mathrm{C}_{12}$ and $\mathrm{C}_{18}$ alkylated complexes of a related complex $\left[\mathrm{Mn}\left(3-\mathrm{OMe}-\mathrm{sal}_{2} 323\right)\right]^{+}$which was also shown to persist in the HS state across a wide temperature range.

\section{Results and Discussion}

\subsection{Synthetic Route to Complexes (1)-(12)}

The reaction between 1,2-bis(3-aminopropylamino)ethane and two equivalents of 4,6-dimethoxysalicylaldehyde resulted in the formation of the Schiff-base ligand $\mathbf{H}_{\mathbf{2}} \mathbf{( 4 , 6 -}$ diOMe-sal 2323)] which was utilized for complexation as shown in Figure 1. In the synthesis of complexes 1-5, an appropriate manganese source was added in a one-pot reaction, where complexes 1, 2, and 5, were produced using the relevant manganese salt, while preparation of complexes 3 and 4 utilized a salt metathesis procedure starting with hydrated manganese(II) chloride. This resulted in a bulk sample of red crystals of complexes 1-4, whilst 5 was isolated as a single crystal inside an oil. As such only structural data will be presented for the chloride complex 5.
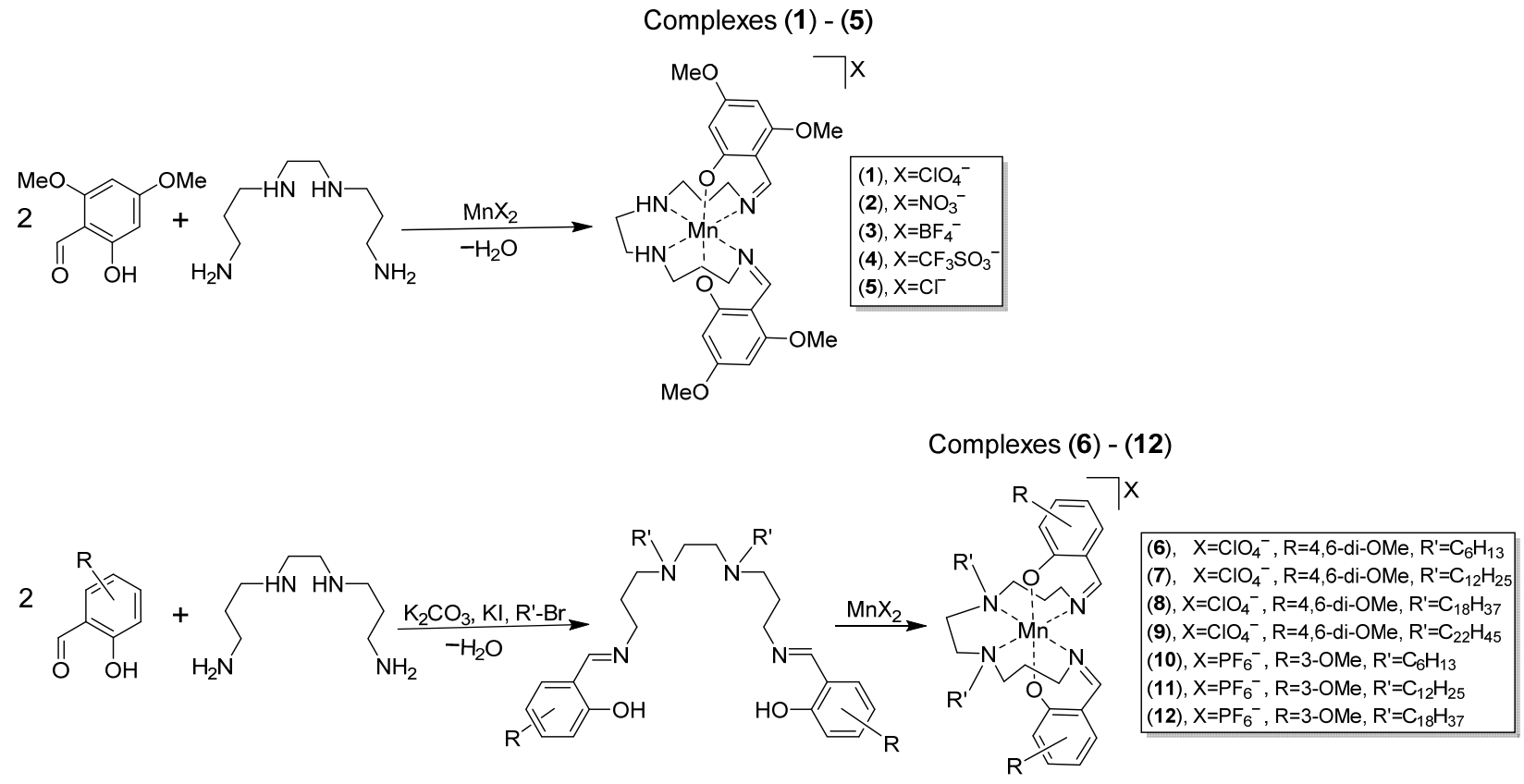

Figure 1. Synthetic route to complexes (1)-(12). 
The synthesis of complexes 6-9, proceeded with the addition of the appropriate bromoalkane $\left(\mathrm{C}_{6}, \mathrm{C}_{12}, \mathrm{C}_{18}\right.$, or $\left.\mathrm{C}_{22}\right)$ to $\mathbf{H}_{2}\left(\mathbf{4}, 6\right.$-diOMe-sal $\left.\left.{ }_{2} 323\right)\right]$ to isolate the intermediate ligands, $\mathbf{H}_{2}$ (4,6-diOMe-sal ${ }_{2} 323-\mathrm{C}_{6}$ ), $\mathbf{H}_{2}\left(4,6-\right.$ diOMe-sal $\left.{ }_{2} 323-\mathrm{C}_{12}\right), \mathbf{H}_{2}$ (4,6-diOMe-sal ${ }_{2} 323-$ $\left.\mathbf{C}_{18}\right)$, and $\mathbf{H}_{\mathbf{2}}\left(\mathbf{4}, \mathbf{6}-\mathrm{diOMe}-\mathbf{s a l}_{\mathbf{2}} \mathbf{3 2 3}-\mathrm{C}_{\mathbf{2 2}}\right)$. These ligands were then reacted with hydrated manganese(II) perchlorate which resulted in red crystals of complexes 6 and 7, and powders of complexes $\mathbf{8}$ and $\mathbf{9}$ after standing in air. The synthesis of complexes 10-12 used an analogous route starting with 3-methoxysalicylaldehyde to prepare ligands $\mathbf{H}_{\mathbf{2}}(\mathbf{3}-\mathbf{O M e}$ sal $\left._{2} 323-C_{6}\right), \mathbf{H}_{2}$ (3-OMe-sal $2323-C_{12}$ ), and $\mathbf{H}_{2}$ (3-OMe-sal ${ }_{2} 323-C_{18}$ ), followed by complexation which yielded red crystals of complexes 10-12. In all cases where crystals were isolated, single crystal X-ray diffraction was used to collect structural data. Full details of the formulae for complexes (1)-(12) can be found in Table 1.

Table 1. Mn(III) complexes with 4,6-diOMe-sal 2323 and related alkylated ligands.

\begin{tabular}{|c|c|}
\hline Compound & Formula * \\
\hline$(1) *$ & {$\left[\mathrm{Mn}\left(4,6-\mathrm{diOMe}-\mathrm{sal}_{2} 323\right)\right] \mathrm{ClO}_{4} \cdot 0.5 \mathrm{H}_{2} \mathrm{O}$} \\
\hline$(2)$ * & {$\left[\mathrm{Mn}\left(4,6-\mathrm{diOMe}-\mathrm{sal}_{2} 323\right)\right] \mathrm{NO}_{3} \cdot 1.15 \mathrm{H}_{2} \mathrm{O}$} \\
\hline (3) * & {$\left[\mathrm{Mn}\left(4,6-\mathrm{diOMe}-\mathrm{sal}_{2} 323\right)\right] \mathrm{BF}_{4} \cdot 0.85 \mathrm{H}_{2} \mathrm{O}$} \\
\hline$(4)$ * & 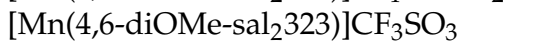 \\
\hline$(5)$ * & {$\left[\mathrm{Mn}\left(4,6-\mathrm{diOMe}-\mathrm{sal}_{2} 323\right)\right] \mathrm{Cl} \cdot \mathrm{C}_{2} \mathrm{H}_{5} \mathrm{OH}$} \\
\hline (6) * & {$\left[\mathrm{Mn}\left(4,6-\mathrm{diOMe}^{-\mathrm{sal}_{2} 323-}\right.\right.$} \\
\hline$(6)^{*}$ & $\left.\left.\mathrm{C}_{6}\right)\right]\left(\mathrm{BF}_{4}\right)_{0.8}\left(\mathrm{ClO}_{4}\right)_{0.2} \cdot 2 \mathrm{CH}_{3} \mathrm{OH}$ \\
\hline$(7) *$ & 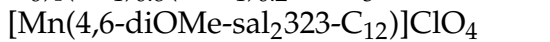 \\
\hline$(8)$ & 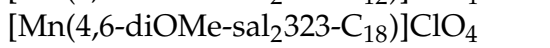 \\
\hline (9) & 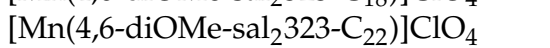 \\
\hline$(10)^{*}$ & {$\left[\mathrm{Mn}\left(3-\mathrm{OMe}-\mathrm{sal}_{2} 323-\mathrm{C}_{6}\right)\right] \mathrm{PF}_{6}$} \\
\hline$(11) *$ & {$\left[\mathrm{Mn}\left(3-\mathrm{OMe}-\mathrm{sal}_{2} 323-\mathrm{C}_{12}\right)\right] \mathrm{PF}_{6} \cdot \mathrm{CH}_{3} \mathrm{CN}$} \\
\hline$(12) *$ & {$\left[\mathrm{Mn}\left(3-\mathrm{OMe}-\mathrm{sal}_{2} 323-\mathrm{C}_{18}\right)\right] \mathrm{PF}_{6} \cdot \mathrm{CH}_{2} \mathrm{Cl}_{2}$} \\
\hline
\end{tabular}

${ }^{*}$ Formula taken from single crystal X-ray diffraction.

\subsection{Magnetic Characterisation of Complexes (1)-(12)}

The magnetic susceptibility of the bulk samples of compounds 1-4 were measured using a SQUID magnetometer and the data was collected between $300 \mathrm{~K}$ and $10 \mathrm{~K}$ with a cooling rate of $10 \mathrm{~K} / \mathrm{min}$ and a scan interval of $5 \mathrm{~K}$. All four complexes were measured using an applied dc field of 5000 Øe. Hysteretic behavior was not observed in the thermal response for any of the compounds. A bulk sample of complex (5) could not be cleanly obtained so the magnetic properties are not reported here.

Complexes 1-4 exhibit incomplete spin crossover behavior, all showing low spin behavior with $\chi \mathrm{T} \approx 1.00 \mathrm{~cm}^{3} \mathrm{~mol}^{-1} \mathrm{~K}$ between $25 \mathrm{~K}$ and $150 \mathrm{~K}$ at which point gradual spin crossover starts to occur. By $300 \mathrm{~K}$, none of the complexes had reached a fully high spin state where a value of $\chi \mathrm{T} \approx 3.00 \mathrm{~cm}^{3} \mathrm{~mol}^{-1} \mathrm{~K}$ would be expected, instead values ranging between 1.98-2.22 $\mathrm{cm}^{3} \mathrm{~mol}^{-1} \mathrm{~K}$ are observed (Figure 2). Whilst the spin crossover transitions are incomplete, it is clear that $\left[\mathrm{Mn}\left(4,6-\mathrm{diOMe}_{\mathrm{Sal}} \mathrm{H}_{23}\right)\right]^{+}$undergoes thermal spin crossover in four different crystalline lattices.

In our previous work with iron(III) complexes with similar ligands we observed that the addition of a long alkyl-chain could modulate the SCO behavior whilst often retaining the spin transition $[55,63]$. In this work, upon replacing a hydrogen atom on the back-bone 323 amine with a long alkyl chain, 6-12, the spin crossover behavior is fully quenched, and instead the complexes remain high spin across the entire temperature range (Figure 3 ).

\subsection{Structural Characterisation of Non-Alkylated SCO Complexes (1)-(5)}

Single crystal structural data was obtained for complexes 1-5 recorded at a temperature of $100 \mathrm{~K}$. All five complexes contain a single complete molecule of [Mn(4,6-diOMe-sal 2323$)]^{+}$ and the respective anion in the asymmetric unit, shown here for complex 1 (Figure $4 \mathrm{a}$ ). The hexadentate Schiff base ligand chelates the metal center resulting in octahedral geometry with two cis-amine, two cis-imine and two trans-phenolate donors. This [Mn(R-sal 2323$)]^{+}$ 
coordination motif is widely known in the spin crossover literature with many related examples previously published. Despite the different space groups (Tables S1-S4), the $\left[\mathrm{Mn}\left(4,6-\text { diOMe-sal }_{2} 323\right)\right]^{+}$cation exhibits the same local geometry in all five lattices, which

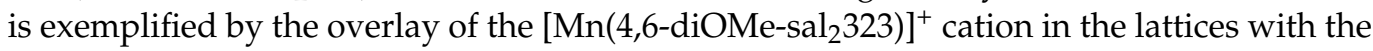
relatively small $\mathrm{Cl}^{-}$(5) and more sterically demanding $\mathrm{ClO}_{4}{ }^{-}$(1) anions (Figure 4b).

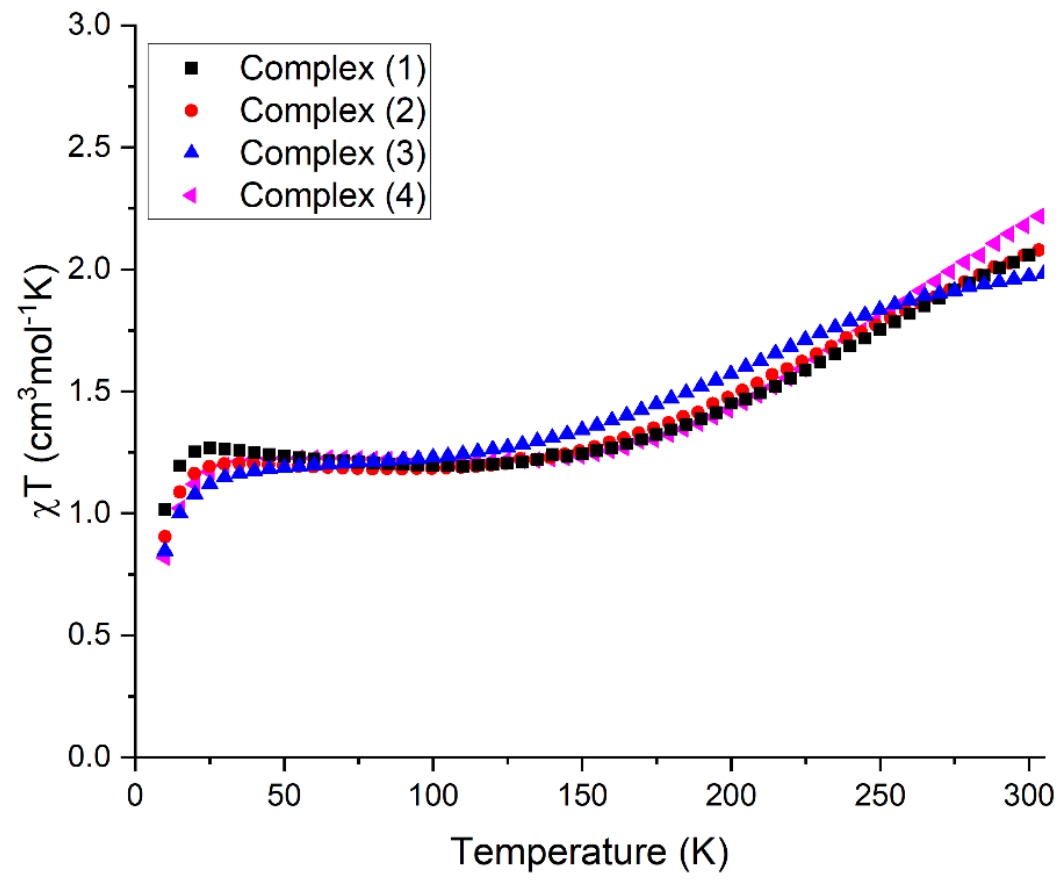

Figure 2. Temperature dependence of $\mathrm{X}_{\mathrm{M}} \mathrm{T}$ for the $\mathrm{Mn}(\mathrm{III})$ complexes 1-4. Data collected in an applied DC field of $0.5 \mathrm{~T}$.

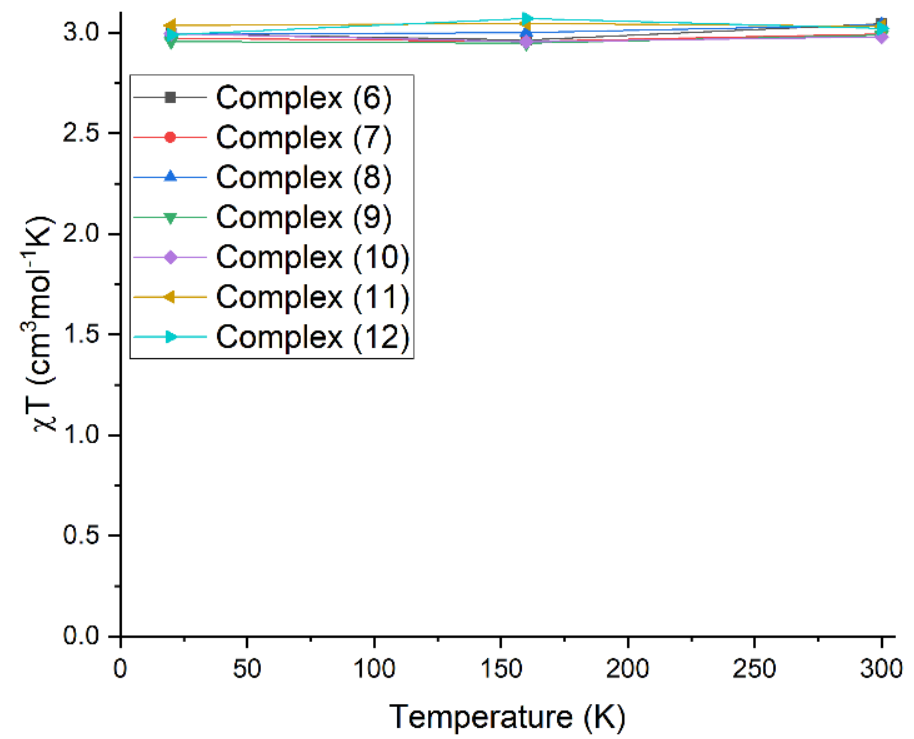

Figure 3. Temperature dependence of $\mathrm{X}_{\mathrm{M}} \mathrm{T}$ for the $\mathrm{Mn}(\mathrm{III})$ complexes 6-12. Data collected at 300, 160, and $10 \mathrm{~K}$ under an applied DC field of $0.5 \mathrm{~T}$. 


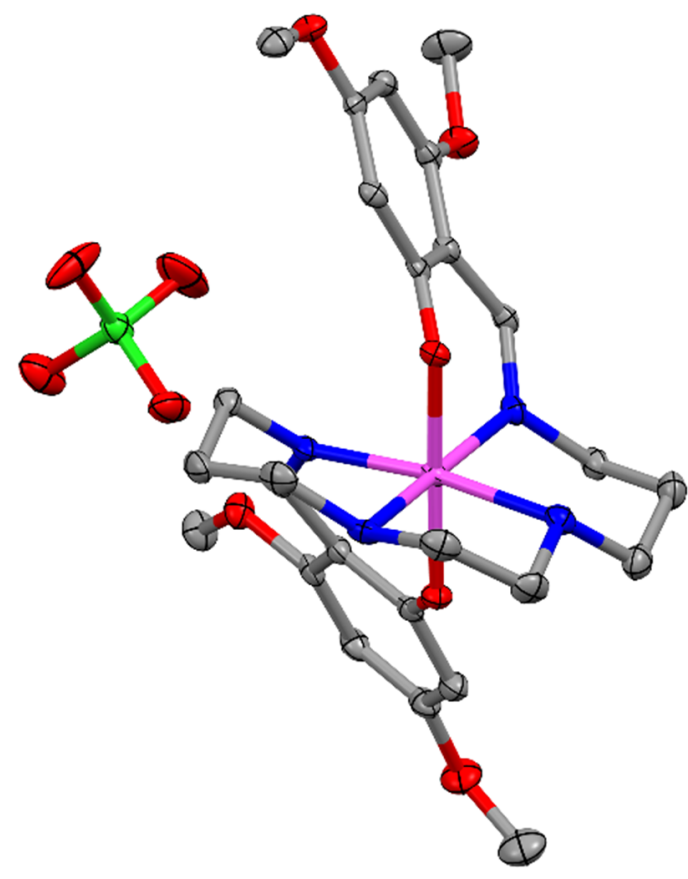

(a)

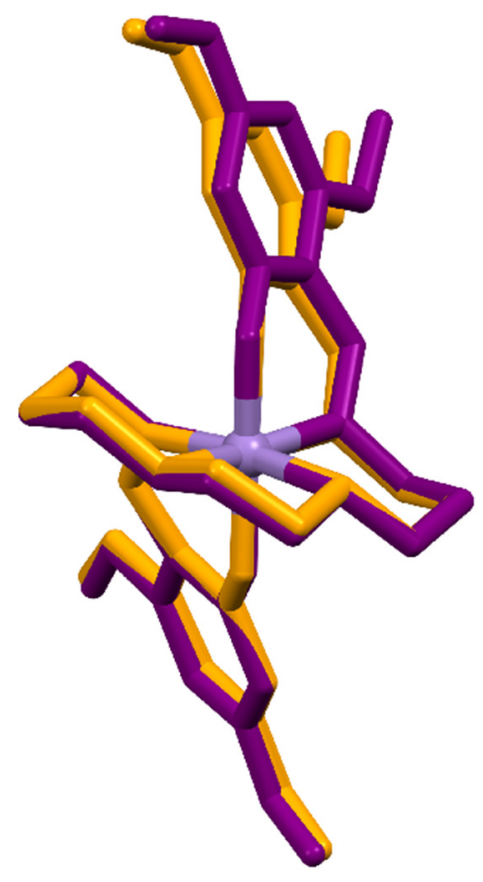

(b)

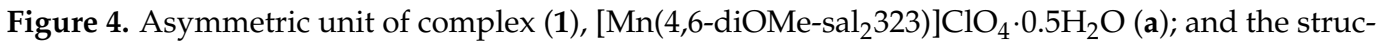
tural overlap of the cationic species, $\left[\mathrm{Mn}\left(4,6-\mathrm{diOMe}_{-} \mathrm{sal}_{2} 323\right)\right]^{+}$, of complex (1) $[\mathrm{Mn}(4,6-\mathrm{diOMe}-$ $\left.\left.\mathrm{sal}_{2} 323\right)\right] \mathrm{ClO}_{4} \cdot 0.5 \mathrm{H}_{2} \mathrm{O}$, (orange), and complex (5) $\left[\mathrm{Mn}\left(4,6-\right.\right.$ diOMe-sal $\left.\left._{2} 323\right)\right] \mathrm{Cl} \cdot \mathrm{C}_{2} \mathrm{H}_{5} \mathrm{OH}$ (purple) at $100 \mathrm{~K}(\mathbf{b})$. Interstitial solvent molecules and hydrogen atoms omitted for clarity.

Complex (1) features a single hydrogen bond between an amine nitrogen of the ligand backbone and an oxygen of the perchlorate anion [N3 $\cdots \mathrm{O} 7=3.049 \AA$ and $<(\mathrm{NH} \cdots \mathrm{O})=152^{\circ}$ ] with no other major contributions to the long-range order. A similar pattern is clear across the entire series of complexes 1-5. We observe two long-range packing modes in this family of structures with complexes $1\left(\mathrm{P} 2{ }_{1} / \mathrm{n}\right), 4(\mathrm{P}-1)$, and $5\left(\mathrm{P} 2{ }_{1} 2_{1} 2_{1}\right)$ (Figure $\left.5 \mathrm{a}, \mathrm{d}, \mathrm{e}\right)$ all featuring remarkably similar, herring-bone type, long-range order, whilst complexes $2\left(\mathrm{P} 2{ }_{1} / \mathrm{c}\right)$ and 3 $\left(\mathrm{P} 2_{1} / \mathrm{c}\right)$ packing in an $\mathrm{AB}$ type layered structure (Figure $5 \mathrm{~b}, \mathrm{c}$ ).

Unlike non-chelating Mn(III) SCO complexes which can often show changes in all bond lengths around the metal center, SCO compounds of this class of ligand, [Mn(R$\left.\left.\mathrm{sal}_{2} 323\right)\right]^{+}$, usually only exhibit significant bond length changes in the equatorial bonds between the metal center and the four imine and amine nitrogen atoms. In this class of chelating complex, literature values for the LS and HS states of the $\mathrm{Mn}-\mathrm{N}_{\text {imine }}$ bond are 1.9-2.0 $\AA$ to 2.1-2.2 $\AA$ respectively and 2.0-2.1 $\AA$ to 2.2-2.3 $\AA$ for the Mn- $\mathrm{N}_{\text {amine }}$ LS and HS states respectively.

In addition to the changes in bond lengths, six-coordinate octahedral Mn(III) compounds exhibit very little deviation from the perfect octahedral shape in the $S=1$ state, whereas in the $S=2$ state there is a large degree of distortion due to the Jahn-Teller effect. The degree of distortion can be quantified by two distortion parameters, $\sum$ and $\Theta$. $\sum$ defines the angular distortion of the twelve cis octahedral angles from $90^{\circ}$, and $\Theta$ measures the trigonal torsion of the perfect octahedral environment towards trigonal prismatic geometry. These parameters can be quickly obtained with the opensource software OctaDist 2.6.1 [69]. In an idealized example, a perfect octahedron would have values of zero for both parameters, however, literature values for $\mathrm{Mn}(\mathrm{III})$ compounds give a reasonable basis for spin state assignment (Table 2) [8,12]. 


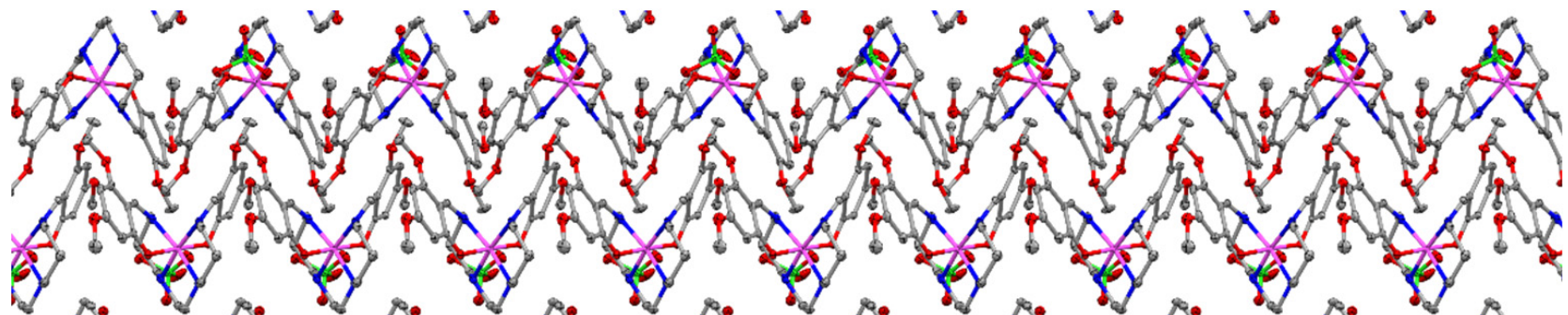
等

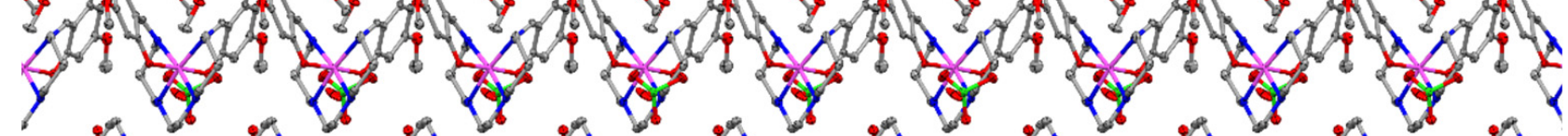

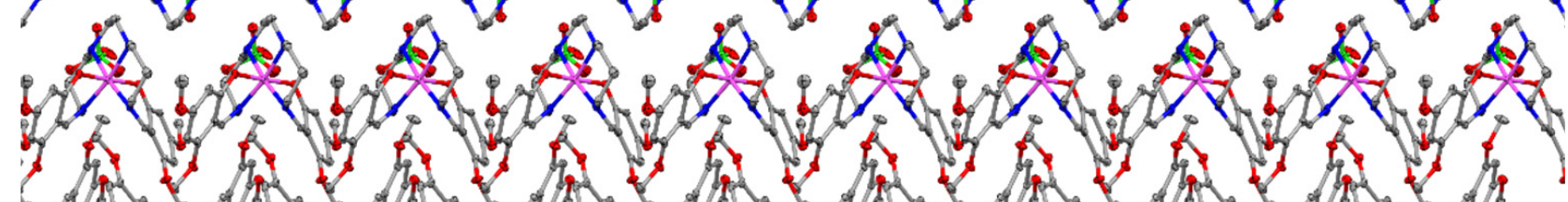

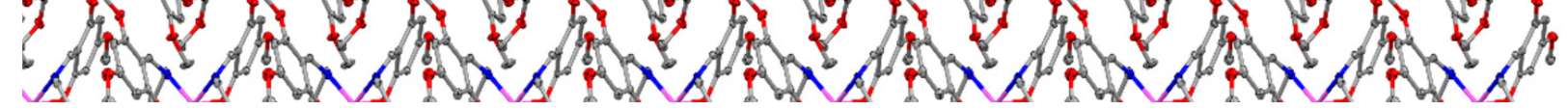

(a)

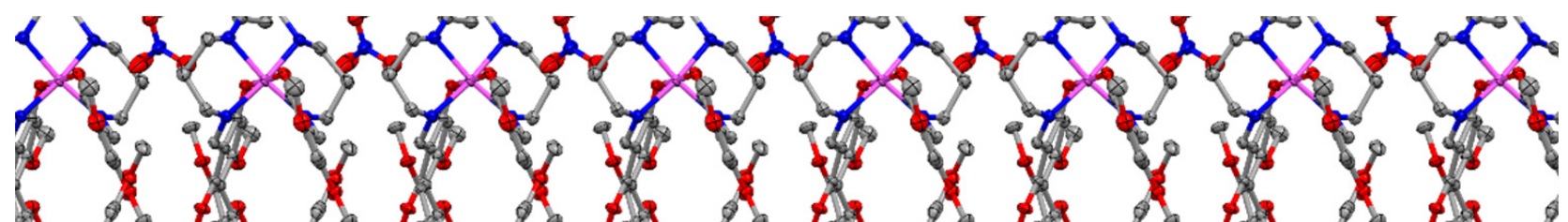
2. Lo 302 L

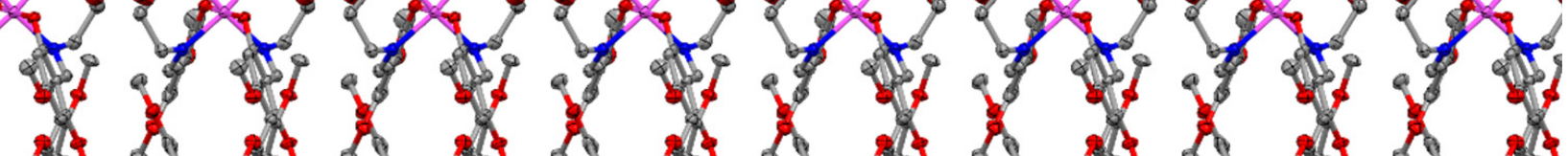
\% L - 1 .

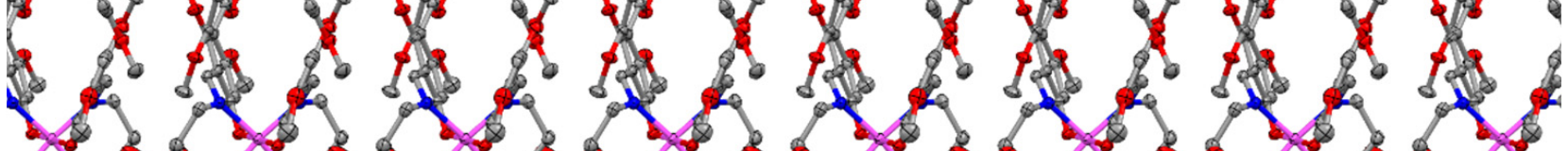
(b) 


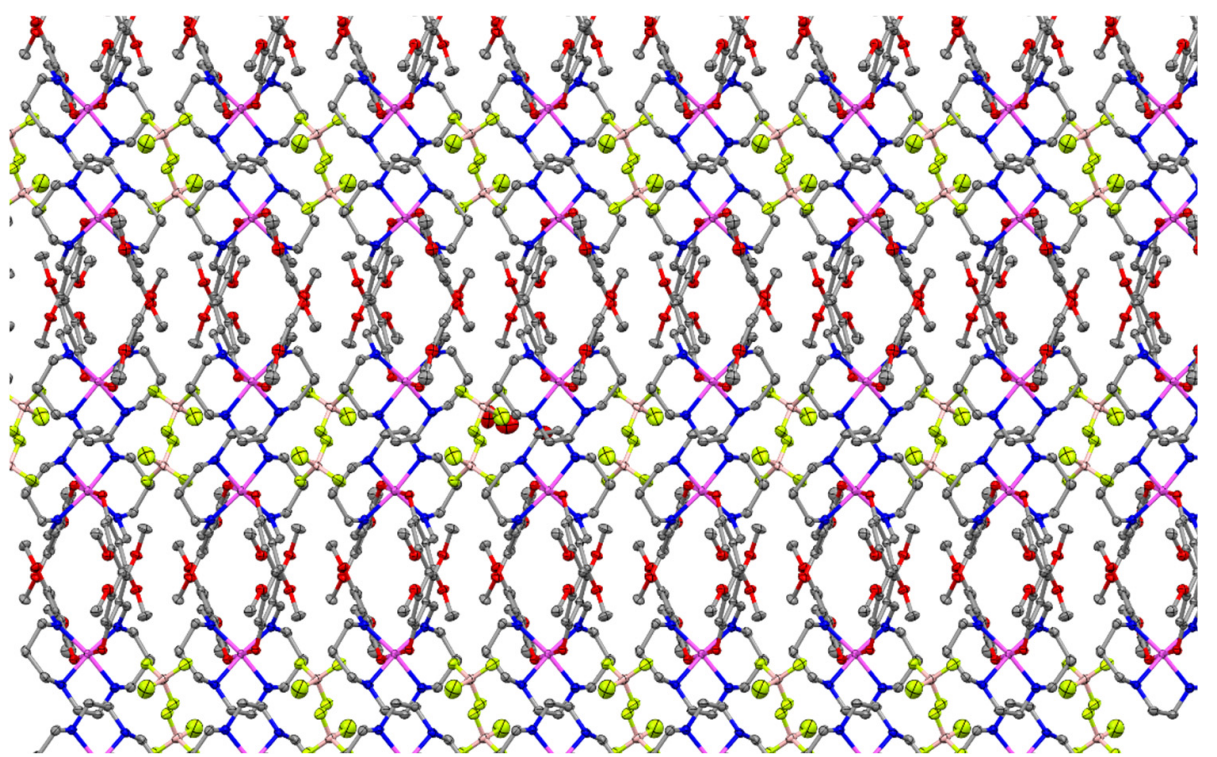

(c)

\% Ant

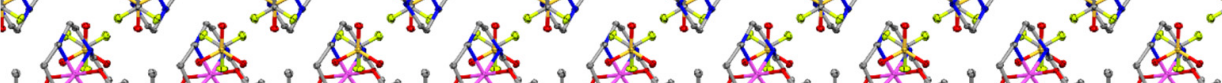

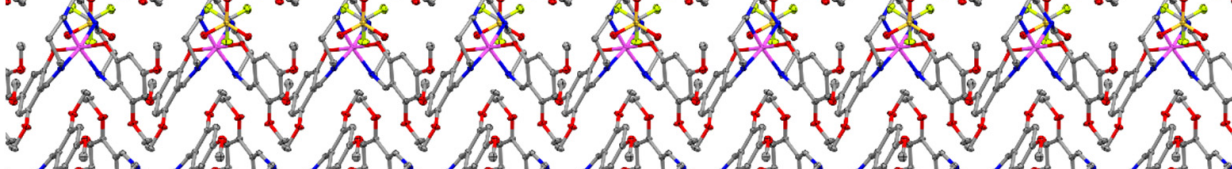

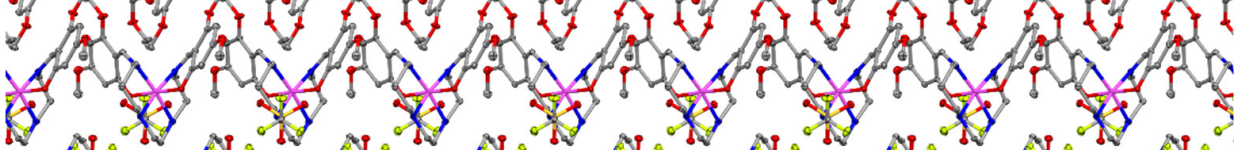

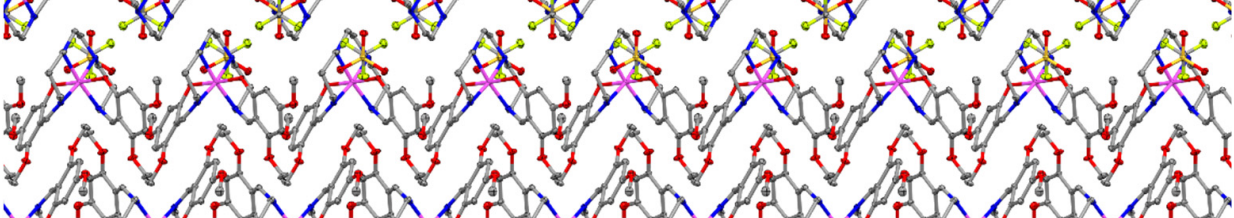

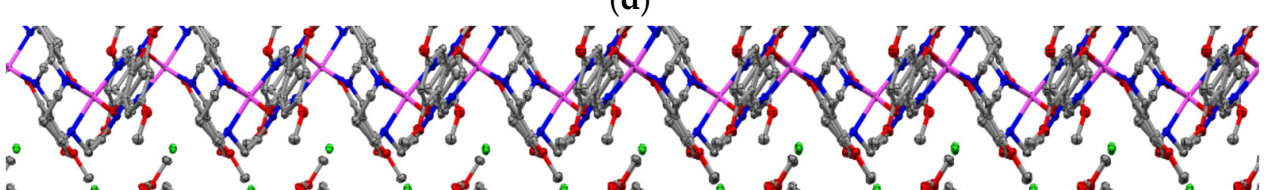

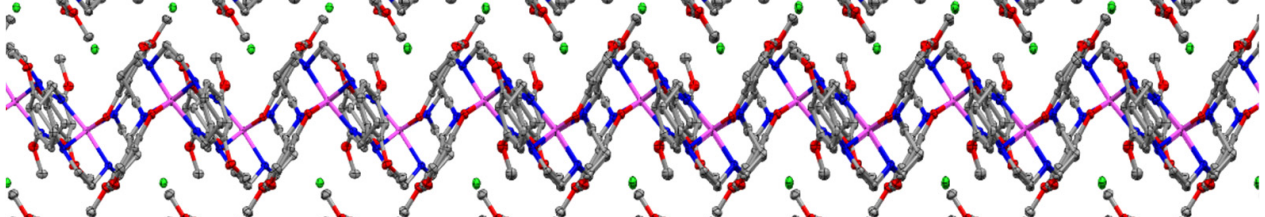
2. H o

(e)

Figure 5. Long range order present in the structures of the $\mathrm{P} 2_{1} / \mathrm{n}$ complex (1), $[\mathrm{Mn}(4,6-\mathrm{diOMe}-$ $\left.\left.\mathrm{sal}_{2} 323\right)\right] \mathrm{ClO}_{4} \cdot 0.5 \mathrm{H}_{2} \mathrm{O}(\mathbf{a})$, the $\mathrm{P}_{1} /$ c complex (2), $\left[\mathrm{Mn}\left(4,6-\mathrm{diOMe}_{-} \mathrm{sal}_{2} 323\right)\right] \mathrm{NO}_{3} \cdot 1.15 \mathrm{H}_{2} \mathrm{O}$ 
(b), the $\mathrm{P}_{1}$ / c complex (3), [Mn(4,6-diOMe- $\left.\left.\mathrm{sal}_{2} 323\right)\right] \mathrm{BF}_{4} \cdot 0.85 \mathrm{H}_{2} \mathrm{O}$ (c), the P-1 complex (4), [Mn(4,6diOMe-sal $\left.\left.{ }_{2} 323\right)\right] \mathrm{CF}_{3} \mathrm{SO}_{3}(\mathbf{d})$, and the $\mathrm{P}_{2}{ }_{2}{ }_{1} 2_{1}$ complex (5), [Mn(4,6-diOMe-sal $\left.\left.{ }_{2} 323\right)\right] \mathrm{Cl} \cdot \mathrm{C}_{2} \mathrm{H}_{5} \mathrm{OH}(\mathbf{e})$. All shown down the c-axis. Hydrogen atoms omitted for clarity.

Table 2. Previously observed values for $\sum$ and $\Theta$ in this class of SCO compounds.

\begin{tabular}{ccc}
\hline Spin State & $\sum$ & $\Theta$ \\
\hline$S=1$ & $28-45^{\circ}$ & $79-125^{\circ}$ \\
$S=2$ & $48-80^{\circ}$ & $135-230^{\circ}$ \\
\hline
\end{tabular}

The magnetic data for compounds 1-4 suggests the complexes are in the low spin state at $100 \mathrm{~K}$ and given the trend it would also be expected that complex 5, where a bulk sample was unobtainable, would also be LS. This is supported by all aspects of the structural data (Table 3).

Table 3. Metal-ligand bond lengths and distortion angle parameters, $\sum$ (angular deviation at the origin) and $\Theta$ (trigonal torsion angle) for complexes $\mathbf{1}-\mathbf{5}$ at $100 \mathrm{~K}$.

\begin{tabular}{cccccc}
\hline & $\mathbf{( 1 )}$ & $\mathbf{( 2 )}$ & $\mathbf{( 3 )}$ & $\mathbf{( 4 )}$ & $\mathbf{( 5 )}$ \\
\hline $\mathrm{Mn}^{-\mathrm{O}_{\text {phen }}}$ & 1.889 & 1.894 & 1.890 & 1.885 & 1.885 \\
$(\AA)$ & 1.896 & 1.896 & 1.899 & 1.899 & 1.888 \\
$\mathrm{Mn}^{-\mathrm{N}_{\text {imine }}}$ & 1.976 & 1.987 & 1.980 & 1.982 & 1.979 \\
$(\AA)$ & 1.985 & 1.987 & 1.985 & 1.981 & 1.989 \\
$\mathrm{Mn}-\mathrm{N}_{\text {amine }}$ & 2.053 & 2.054 & 2.057 & 2.057 & 2.040 \\
$(\AA)$ & 2.054 & 2.057 & 2.057 & 2.058 & 2.054 \\
$\sum^{\circ}$ & 33.4 & 32.9 & 33.6 & 28.6 & 33.9 \\
$\Theta^{\circ}$ & 99.9 & 101.1 & 101.0 & 82.1 & 97.2 \\
Assignment & $\mathrm{S}=1$ & $\mathrm{~S}=1$ & $\mathrm{~S}=1$ & $\mathrm{~S}=1$ & $\mathrm{~S}=1$ \\
\hline
\end{tabular}

\subsection{Structural Characterisation of Alkylated SCO Complexes (6)-(12)}

The amphiphilic complexes 6, 7, and 10-12 also crystallize in a range of space groups, and, as with their non-alkylated counterparts, all feature a single Mn(III) cation and the relevant anion in the asymmetric unit cell. Each complex features the same local Mn(III) geometry which also aligns with the geometry of the non-alkylated complexes, even between spin states, as shown by the overlay between complexes $\mathbf{1}$ (low spin) and $\mathbf{6}$ (high spin) (Figure 6).

The alkylated complexes feature two equal length alkyl chains, on the 323 amine backbone attached through the amine nitrogen atoms. The amine nitrogen atoms are located at cis positions and due to the nature of the backbone are in a non-meso configuration, as such one chain is located above the equatorial plane whilst the other points below the equatorial plane. This directional aspect of the alkyl chains is preserved for all observed chain lengths, with examples for $C_{6}, C_{12}$, and $C_{18}$ chains presented here (Figures 6 and 7).

The role these perpendicular alkyl chains play in the long-range packing can be pronounced. Instead of the herringbone structure, which was largely observed before, the cations are now dispersed within the alkylated matrix (Figures S1-S4), this is highlighted at the extreme end with the $\mathrm{C}_{18}$ containing complex 12 in Figure 8, which shows the view down the a-axis (a) and the b-axis (b). 


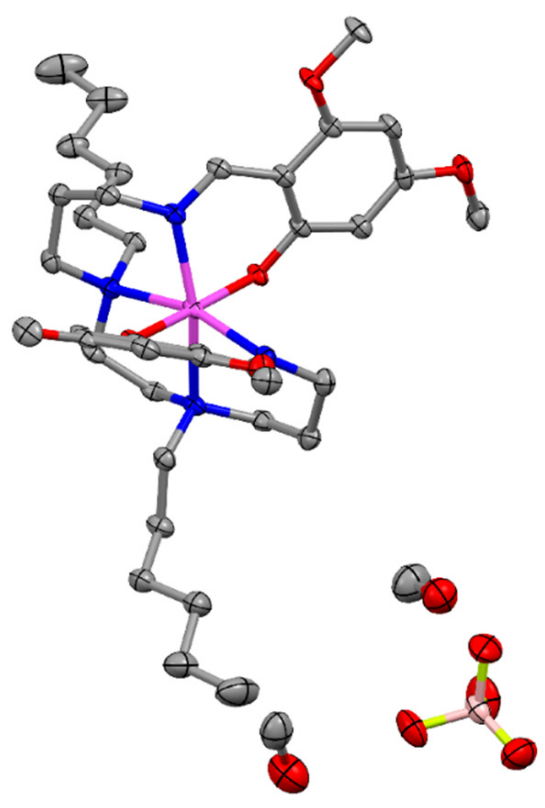

(a)

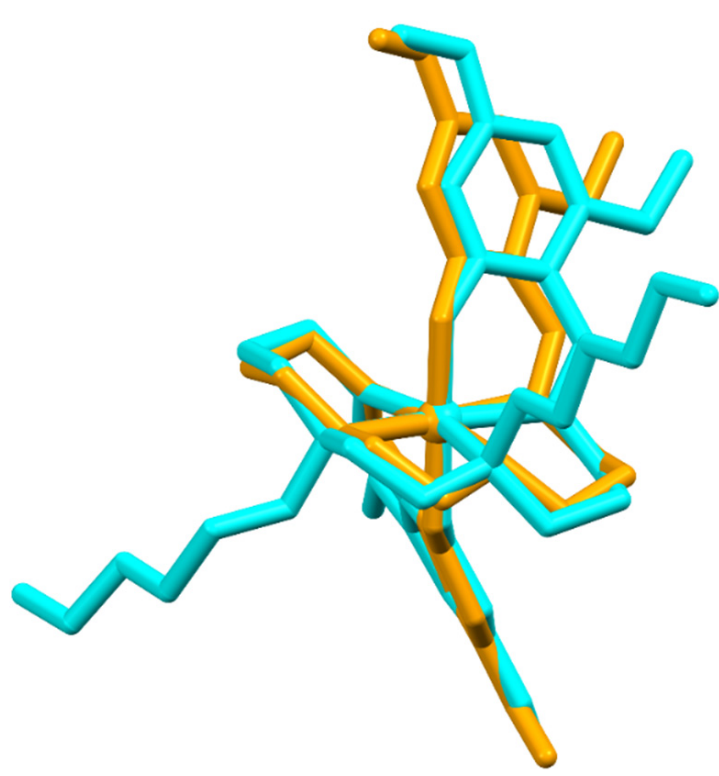

(b)

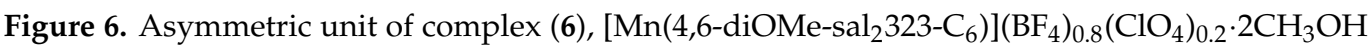
(a); and the structural overlap of the cationic species, [Mn(4,6-diOMe-sal 2323$)]^{+}$, of complex (1) $\left[\mathrm{Mn}\left(4,6\right.\right.$-diOMe- $\left.\left.\mathrm{sal}_{2} 323\right)\right] \mathrm{ClO}_{4} \cdot 0.5 \mathrm{H}_{2} \mathrm{O}$, (orange), and complex (6) [ Mn(4,6-diOMe-sal $2323-$ $\left.\left.\mathrm{C}_{6}\right)\right]\left(\mathrm{BF}_{4}\right)_{0.8}\left(\mathrm{ClO}_{4}\right)_{0.2} \cdot 2 \mathrm{CH}_{3} \mathrm{OH}$ (turquoise) $(\mathbf{b})$. Data collected at $100 \mathrm{~K}$, interstitial solvent molecules, minor anionic component and hydrogen atoms omitted for clarity.

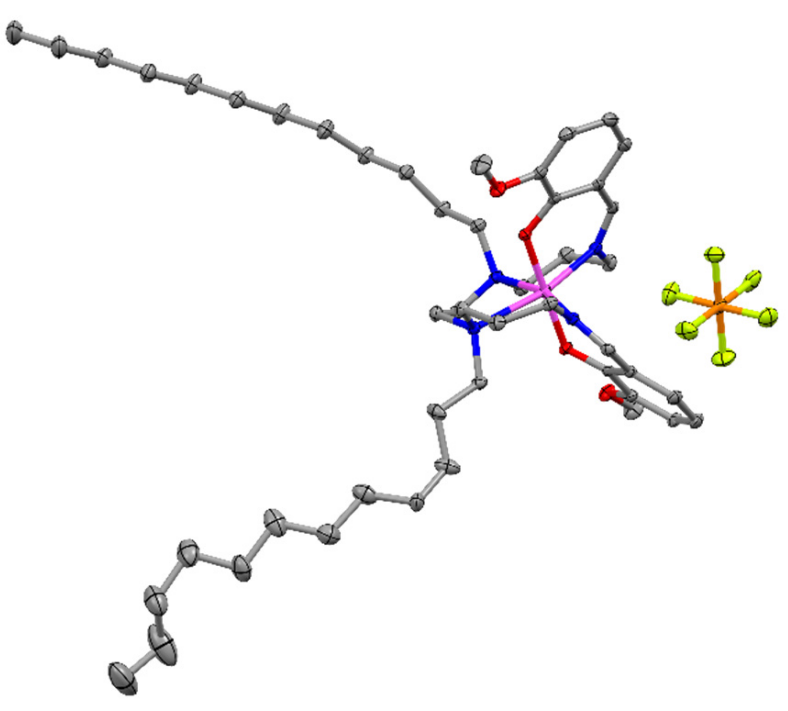

(a)

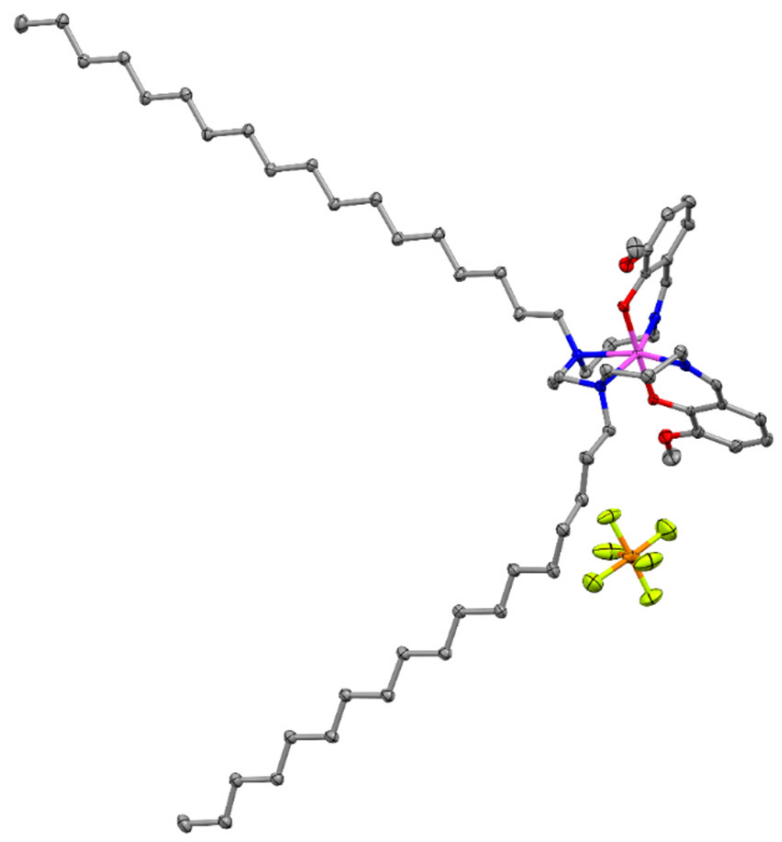

(b)

Figure 7. Asymmetric unit of the $\mathrm{C}_{12}$ containing complex (11), $\left[\mathrm{Mn}\left(3-\mathrm{OMe}-\mathrm{sal}_{2} 323-\mathrm{C}_{12}\right)\right] \mathrm{PF}_{6} \cdot \mathrm{CH}_{3} \mathrm{CN}$ (a); and the $\mathrm{C}_{18}$ containing complex (12), [Mn(3-OMe-sal $\left.\left.2323-\mathrm{C}_{18}\right)\right] \mathrm{PF}_{6} \cdot \mathrm{CH}_{2} \mathrm{Cl}_{2}$ (b). Data collected at $100 \mathrm{~K}$, interstitial solvent molecules and hydrogen atoms omitted for clarity. 


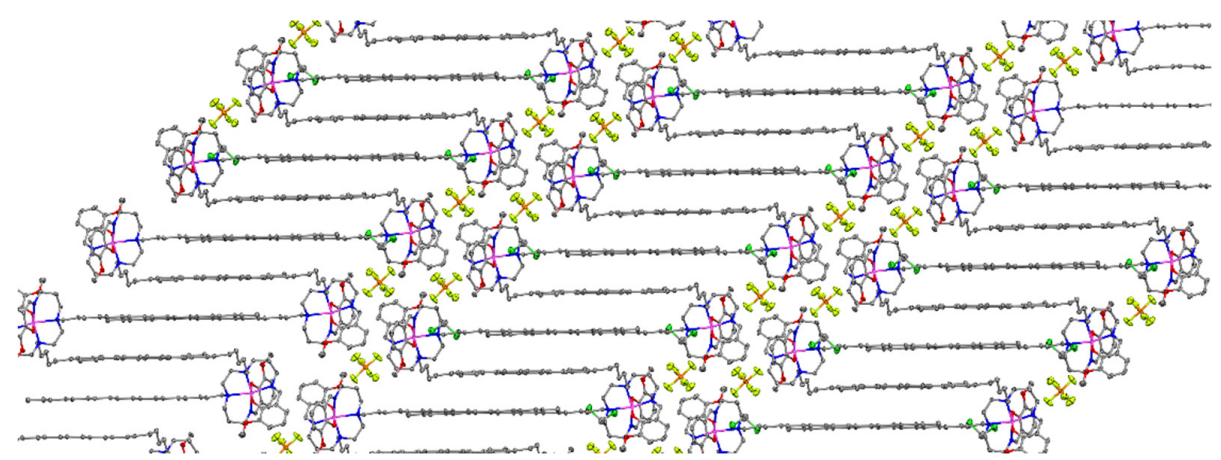

(a)

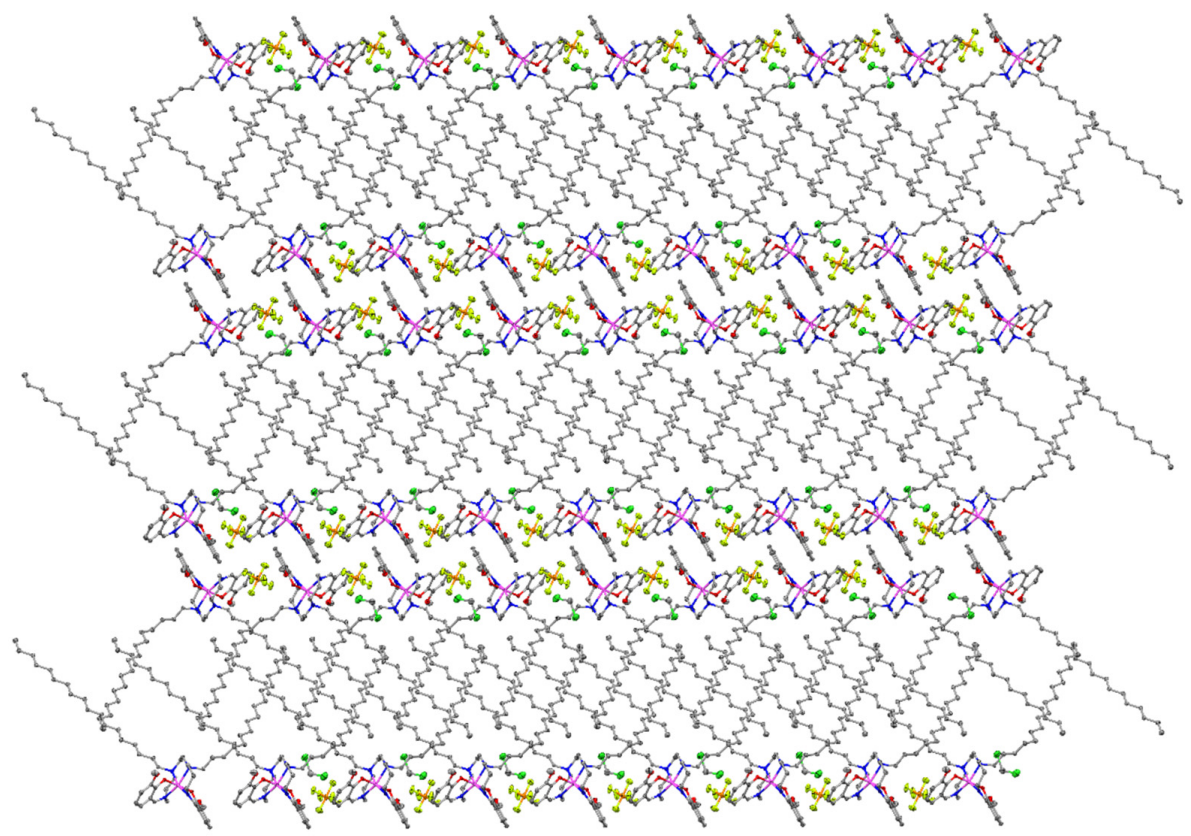

(b)

Figure 8. Long-range order present in the structures of the P-1 complex (12), [Mn(3-OMe-sal $2323-$ $\left.\mathrm{C}_{18}\right) \mathrm{PF}_{6} \cdot \mathrm{CH}_{2} \mathrm{Cl}_{2}$ viewed down the a-axis (a) and the b-axis (b). Data collected at $100 \mathrm{~K}$ and hydrogen atoms and solvent molecules were omitted for clarity.

The magnetic data for complexes 6, 7, and 10-12 indicates that the complexes are high spin across the entire temperature range, including at the $X$-ray measurement temperature of $100 \mathrm{~K}$, which is clear from the structural parameters of the complexes (Table 4).

Table 4. Metal-Ligand bond lengths and distortion angle parameters, $\sum$ (angular deviation at the origin) and $\Theta$ (trigonal torsion angle) for complexes 6, 7, and 10-12 at $100 \mathrm{~K}$.

\begin{tabular}{cccccc}
\hline & $\mathbf{( 6 )}$ & $\mathbf{( 7 )}$ & $\mathbf{( 1 0 )}$ & $\mathbf{( 1 1 )}$ & $\mathbf{( 1 2 )}$ \\
\hline $\mathrm{Mn}^{-\mathrm{O}_{\text {phen }}}$ & 1.860 & 1.866 & 1.857 & 1.857 & 1.861 \\
$(\AA)$ & 1.864 & 1.867 & 1.861 & 1.859 & 1.872 \\
$\mathrm{Mn}-\mathrm{N}_{\text {imine }}$ & 2.076 & 2.087 & 2.104 & 2.091 & 2.086 \\
$(\AA)$ & 2.102 & 2.094 & 2.104 & 2.196 & 2.125 \\
$\mathrm{Mn}^{-N_{\text {amine }}}$ & 2.307 & 2.307 & 2.280 & 2.292 & 2.268 \\
$(\AA)$ & 2.318 & 2.311 & 2.302 & 2.311 & 2.347 \\
$\sum^{\circ}$ & 58.8 & 58.2 & 64.2 & 61.7 & 65.8 \\
$\Theta^{\circ}$ & 246.2 & 241.6 & 250.4 & 233.0 & 239.5 \\
Assignment & $\mathrm{S}=2$ & $\mathrm{~S}=2$ & $\mathrm{~S}=2$ & $\mathrm{~S}=2$ & $\mathrm{~S}=2$ \\
\hline
\end{tabular}


It is noteworthy that the quenching of the spin crossover coincides with enforced separation of the spin labile $\left[\mathrm{Mn}\left(4,6-\mathrm{diOMe}_{-} \mathrm{sal}_{2} 323\right)\right]^{+}$centers in the solid-state structures with alkylated ligands. Whilst there are many examples of iron containing SCO complexes featuring spin transitions in solution [54,70-74], we are not aware of any report on thermal spin crossover in solution for manganese(III). Indeed we could not find any reports of low spin manganese(III) in solution even beyond the spin crossover literature. One potential reason for this discrepancy is the Jahn-Teller effect, which causes large distortions to the octahedral geometry in the Mn(III) HS state. In closely packed solid state Mn(III) structures the complexes can pack in such a way that the energy required to overcome the Jahn-Teller distortion and constrain the spin-labile cations towards an octahedral geometry is gained via packing interactions between neighboring sites leading to a more energetically favorable situation. In solution minimal external pressures are placed onto the complex and the distorted HS state becomes the most favorable configuration. This is evidenced by the overwhelming majority of $\mathrm{Mn}$ (III) complexes found in high spin electronic configurations [75]. In the structures of the five alkylated complexes reported here the $\mathrm{Mn}-\mathrm{N}_{\text {amine }}$ distances are the longest observed to date of complexes of this type, including complexes with other first row transition metal ions. In nearly all cases in the alkylated complexes reported here the Mn-Namine distance exceeds 2.3 angstroms, which represents a difference of close to 0.2 angstroms for the equivalent bond length in the low spin forms of complexes 1-5. We suggest therefore that packing constraints are essential to stabilize the rarer spin triplet form of $\mathrm{Mn}$ (III) and when these are absent (in solution) or diluted (by steric effects as is the case here), the Jahn-Teller effect dominates and stabilizes the spin quintet form.

\subsection{Raman Spectra of Alkylated Complexes (10)-(12)}

The high spin assignment in complexes 10-12 was confirmed by Raman spectra on powdered samples which were measured at room temperature using laser excitation of 633 $\mathrm{nm}$ which is out of resonance with the maximum absorbance of these compounds (Figure 9). Comparison with the data from a comprehensive Raman study of the HS and LS forms of a related complex [76] with no substitution on the phenolate ring was used to interpret the Raman spectra of HS complexes 10-12. In all three structures, the Mn(III) ion is coordinated by pairs of cis imine and amine nitrogen atoms and two trans phenolate oxygen donors, Figures 6 and 7, and the Mn-N and Mn-O modes appear in the low-wavenumber region (100-1000 $\mathrm{cm}^{-1}$ ) along with the same modes mixed with ligand centered motions. The ligand-centered vibrations are concentrated at higher energies between $1000-2000 \mathrm{~cm}^{-1}$. The Raman feature centered around $1300 \mathrm{~cm}^{-1}$ is assigned to an aromatic in-plane ring deformation mode coupled to aromatic $\mathrm{CH}$ and symmetric $\mathrm{O}-\mathrm{Mn}-\mathrm{O}$ deformation while that at $1340 \mathrm{~cm}^{-1}$ is due to the wagging mode of the skeletal $\mathrm{CH}_{2}$ groups. Symmetric O-Mn-O and ring stretch vibrations are assigned to the intense Raman feature at $625 \mathrm{~cm}^{-1}$ while that at $450 \mathrm{~cm}^{-1}$ is due to a moderate intensity Mn-N stretch and aliphatic (imine) and $\mathrm{CH}$ rocking modes. Comparison with Raman spectra in HS and LS states, for the related unsubstituted complex confirm, as expected, that the complexes are in the high spin state. Raman modes at higher energies of $1597 \mathrm{~cm}^{-1}$ and $\approx 1620 \mathrm{~cm}^{-1}$ are assigned to aromatic C-C stretching modes coupled with asymmetric H-C-N stretching and aromatic ring stretch modes. A full list of Raman spectral features can be found in Table S5. In addition to the resonances attributed to the coordination sphere of the metal complex, new features between $1400 \mathrm{~cm}^{-1}$ and $1300 \mathrm{~cm}^{-1}$, which do not appear for the unsubstituted complexes, can be attributed to chain deformation and wagging modes of the alkyl chains. 


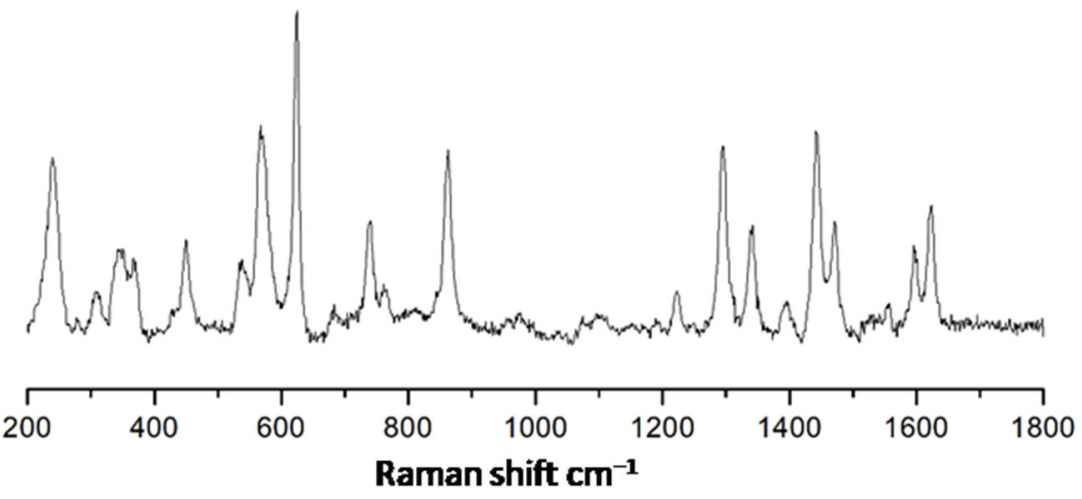

(a)

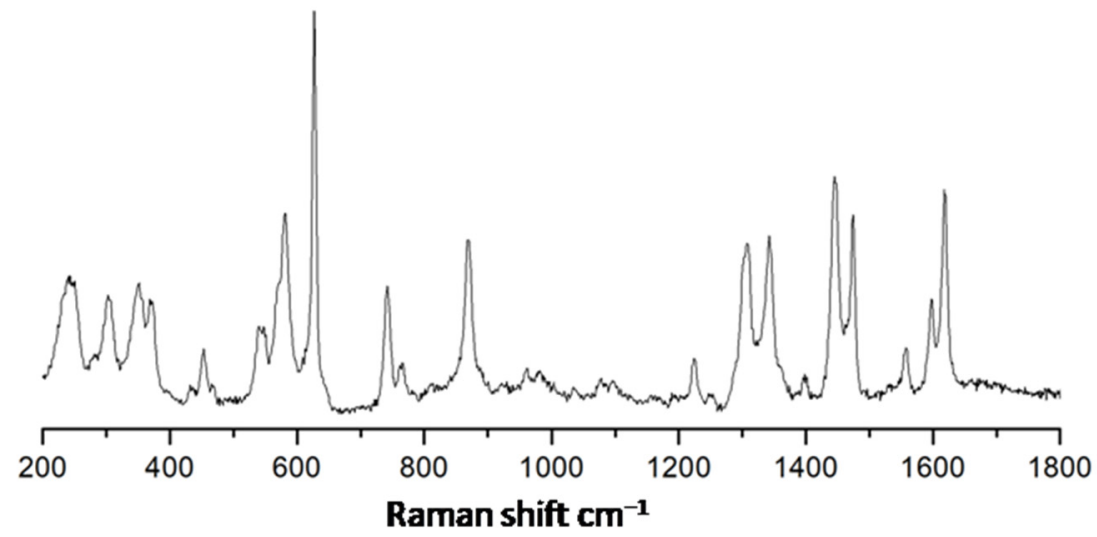

(b)

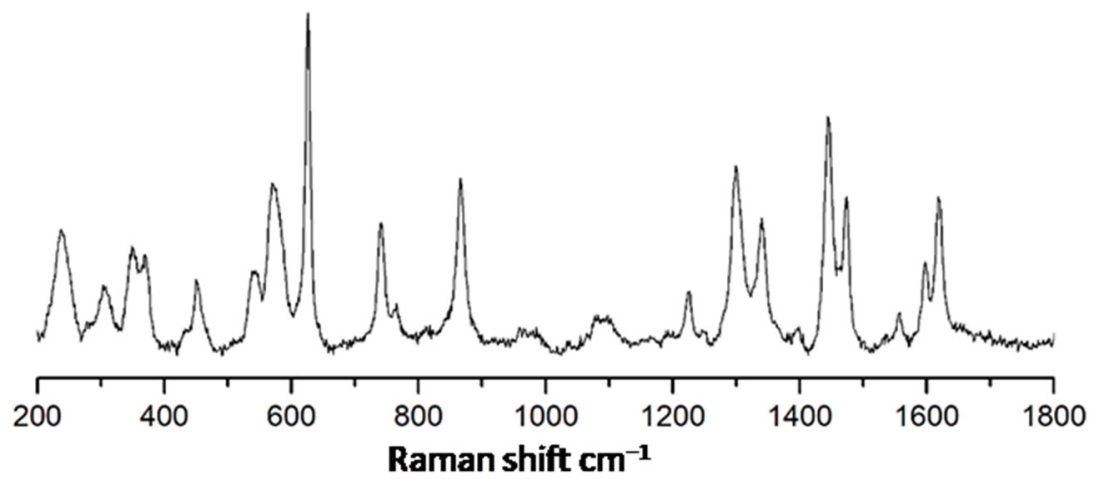

(c)

Figure 9. Room temperature Raman spectra of the alkylated compounds (10)-(12), (a-c), after excitation at $633 \mathrm{~nm}$.

\section{Conclusions}

Analysis of the structural and magnetic data of twelve new Mn(III) complexes reveals the importance of packing and lattice strain in modulating the choice of spin state and accessibility of thermal spin state switching. The efficient packing of the parent compound

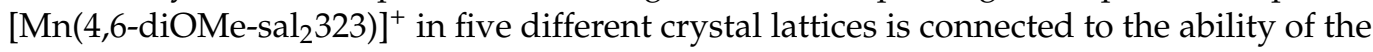
system to undergo thermal spin crossover with the associated volume reduction on cooling. This demonstrates that $\left[\mathrm{Mn}\left(4,6-\mathrm{diOMe}_{-} \mathrm{sal}_{2} 323\right)\right]^{+}$is sufficiently elastic to accommodate the significant bond length changes which accompany thermal switching between the smaller spin triplet form and larger spin quintet form which has a pronounced equatorial elongation due to a pseudo Jahn-Teller effect. Alkylation of the ligand in [Mn(4,6-diOMe$\left.\left.\mathrm{sal}_{2} 323\right)\right]^{+}$results in a significant increase in the inter-cation distances and quenching of 
the thermal spin state switching. The quenching is also observed in alkylated derivatives of the $\mathrm{PF}_{6}{ }^{-}$salt of a related complex $\left[\mathrm{Mn}\left(3-\mathrm{OMe}-\mathrm{sal}_{2} 323\right)\right]^{+}$, where the parent compound is also known to a pronounced spin crossover. We suggest here that the long alkyl chains effectively generate an immobilized solution that reduces the lattice pressure. This in turn means the Jahn-Teller distortion, which is pronounced in the high spin form due to asymmetric population of the anti-bonding orbitals, dominates in the alkylated complexes and cooling alone is not sufficient to promote spin pairing to the spin triplet state. We further suggest that the absence of sufficient local pressure may explain why the spin triplet form of $\mathrm{Mn}$ (III) has not been observed in solution despite several reports in the solid state. We conclude from this study that, in contrast to ferrous or ferric spin crossover systems, alkylation of $\mathrm{Mn}(\mathrm{III})$ complexes may be a less effective route to spin switchable thin films by Langmuir-Blodgett techniques and our work to find alternative routes continues.

\section{Materials and Methods}

\subsection{General Experimental Details}

Physical Measurements. All measurements were carried out on powdered samples of the respective polycrystalline compound. Elemental composition was measured using a Perkin Elmer Vario EL CHN analyser. A Bruker Alpha Platinum spectrometer was used to record the infrared spectra, and mass spectra were recorded on a Waters 2695 Separations Module Electrospray Spectrometer.

Raman Spectra. The Raman spectra were acquired on a sample dispersed in $\mathrm{KBr}$ $(5 \% w / w)$ on a confocal Labrum HR spectrometer from Horiba coupled to a $633 \mathrm{~nm}$ laser source using a $100 \mathrm{X}($ N.A. $=0.90)$ Olympus objective. Spectra were background corrected using a 4-point polynomial generated using Alspec software.

Crystal Data Collection and Refinement. Appropriate single crystals of the relevant complexes were mounted on an Oxford Diffraction Supernova A diffractometer fitted with an Atlas detector; datasets were measured using monochromatic $\mathrm{Cu}-\mathrm{K} \alpha$ radiation or Mo-K $\alpha$ radiation and corrected for absorption [77]. The temperature $(100 \mathrm{~K})$ was controlled with an Oxford ProSystem instrument. Structures were solved by direct methods (SHELXS) and refined with full-matrix least-squared procedures based on $\mathrm{F}^{2}$, using SHELXL-2016 [78]. Non-hydrogen atoms were refined with independent anisotropic displacement parameters, $\mathrm{H}$-atoms were placed in idealized positions. Selected crystallographic data and structure refinements are summarized in Tables S1-S4 and crystallographic data for the structures reported in this paper have been deposited with the Cambridge Crystallographic Data Centre as supplementary publication numbers CCDC-2124577-2124586.

Magnetic Measurements. The magnetic susceptibility measurements were recorded on a Quantum Design SQUID magnetometer MPMS-XL operating between 1.8 and $300 \mathrm{~K}$. DC measurements were performed on polycrystalline samples inside gelatin capsules in an applied field of 5000 Øe. Diamagnetic corrections were applied to account for the gelatin capsule and the long alkyl chains on some complexes.

\subsection{Synthesis and Characterisation of Non-Alkylated Complexes 1-5}

Complex $\left[\mathrm{Mn}\left(4,6-\mathrm{diOMe}-\mathrm{sal}_{2} 323\right)\right] \mathrm{ClO}_{4} \cdot 0.5 \mathrm{H}_{2} \mathrm{O}(1)$. To a well stirred solution of $N, N^{\prime}$-bis(3-aminopropyl)ethylenediamine $(100 \mathrm{mg}, 0.574 \mathrm{mmol})$ in 1:1 methanol:acetonitrile (25 mL) was added 4,6-dimethoxy salicylaldehyde $(209 \mathrm{mg}, 1.15 \mathrm{mmol})$ and the resultant yellow solution was stirred for $15 \mathrm{~min}$. Solid manganese(II) perchlorate hexahydrate (207 mg, $0.574 \mathrm{mmol}$ ) was added and the resulting red colored solution was stirred at RT for $1 \mathrm{~h}$. The reaction mixture was then gravity filtered and the filtrate was left to stand which yielded red colored crystals. Yield: $309 \mathrm{mg}$, 82\%. ESI-MS: $556\left(\mathrm{M}^{+}-\mathrm{ClO}_{4}\right)$. Elemental analysis for $\mathrm{C}_{26} \mathrm{H}_{37} \mathrm{~N}_{4} \mathrm{O}_{10.5} \mathrm{ClMn}=663.99 \mathrm{~g} / \mathrm{mol}^{-1}$ Calculated: \%C 47.03, \%H 5.62, \%N 8.44, Found: \%C 47.45, \%H $5.43 \%$ N 8.36. IR (KBr, $\left.\mathrm{cm}^{-1}\right)$ : 3436, 2957, 1598, 1549, 1453, 1231, $1155,1089,815$ and 623.

Complex $\left[\mathrm{Mn}\left(4,6-\mathrm{diOMe}-\mathrm{sal}_{2} 323\right)\right] \mathrm{NO}_{3} \cdot \mathbf{1 . 1 5}_{2} \mathrm{O}$ (2). To a well stirred solution of $\mathrm{N}, \mathrm{N}^{\prime}$-bis(3-aminopropyl)ethylenediamine $(100 \mathrm{mg}, 0.574 \mathrm{mmol})$ in 1:1 methanol:acetonitrile 
(25 mL) was added 4,6-dimethoxy salicylaldehyde (209 mg, $1.15 \mathrm{mmol}$ ). A yellow color developed and the solution was stirred for $15 \mathrm{~min}$. Solid manganese(II) nitrate tetrahydrate (144 $\mathrm{mg}, 0.574 \mathrm{mmol}$ ) were added to the reaction mixture and the resulting red-colored solution was stirred at RT for $1 \mathrm{~h}$. The reaction mixture was then gravity filtered and the filtrate was left standing to allow crystallization of the complex. Solvent evaporation yielded red-colored crystals. Yield-190 mg, 53.6\%. ESI-MS: $556\left(\mathrm{M}^{+}-\mathrm{NO}_{3}\right)$. Elemental analysis $=\mathrm{C}_{26} \mathrm{H}_{38.30} \mathrm{~N}_{5} \mathrm{O}_{10.15} \mathrm{Mn}=638.26 \mathrm{~g} / \mathrm{mol}^{-1}$ Calculated \%C 48.93, \%H 6.05, \%N 10.97, Found: \%C 49.11, \%H 5.53, \%N 10.97. IR (KBr, cm $\left.{ }^{-1}\right): 3435,3186,2928,1598,1550,1453$, $1420,1384,1231,1155,1130,1045,812$ and 657.

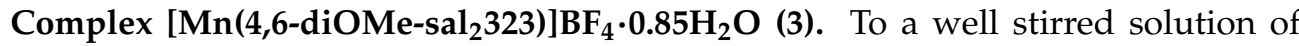
$\mathrm{N}, \mathrm{N}$ '-bis(3-aminopropyl)ethylenediamine (100 mg, $0.574 \mathrm{mmol})$ in 1:1 methanol:acetonitrile (25 mL) was added 4,6-dimethoxy salicylaldehyde (209 mg, $1.15 \mathrm{mmol})$ in 1:1 methanol:acetonitrile $(20 \mathrm{~mL})$. A yellow color was developed, and the solution was stirred for $15 \mathrm{~min}$. Solid manganese(II) chloride tetrahydrate $(113.6 \mathrm{mg}, 0.574 \mathrm{mmol})$ and ammonium tetrafluoroborate $(60 \mathrm{mg}, 0.574 \mathrm{mmol})$ was added to the reaction mixture and the resulting red colored solution was stirred at RT for $1 \mathrm{~h}$. The reaction mixture was then gravity filtered and the filtrate was left standing to allow crystallization of the complex. Solvent evaporation yielded red colored crystals. Yield-200 mg, 54.2\%. ESI-MS: $556\left(\mathrm{M}^{+}-\mathrm{BF}_{4}\right)$. Elemental analysis: $\mathrm{C}_{26} \mathrm{H}_{37.70} \mathrm{BN}_{4} \mathrm{O}_{6.85} \mathrm{~F}_{4} \mathrm{Mn}=657.65 \mathrm{~g} / \mathrm{mol}^{-1}$ Calculated: $\% \mathrm{C} 47.49, \% \mathrm{H} 5.78, \% \mathrm{~N}$ 8.52, Found: \%C 47.89, \%H 5.71 \%N 8.47. IR (KBr, $\left.\mathrm{cm}^{-1}\right): 3267,2929,1598,1550,1453,1420$, $1336,1231,1156,1130,1068,815$ and 660.

Complex $\left[\mathrm{Mn}\left(4,6-\mathrm{diOMe}-\mathrm{sal}_{2} 323\right)\right] \mathrm{CF}_{3} \mathrm{SO}_{3}$ (4). To a well stirred solution of $\mathrm{N}, \mathrm{N}^{\prime}-$ bis(3-aminopropyl)ethylenediamine $(100 \mathrm{mg}, 0.574 \mathrm{mmol})$ in $1: 1$ methanol:acetonitrile (25 mL) was added 4,6-dimethoxysalicylaldehyde $(209 \mathrm{mg}, 1.15 \mathrm{mmol})$ in 1:1 methanol:acetonitrile $(20 \mathrm{~mL})$. A yellow color developed and the solution was stirred for $15 \mathrm{~min}$. Manganese(II) trifluoromethanesulfonate $(203 \mathrm{mg}, 0.574 \mathrm{mmol})$ was then added and the resulting red colored solution was stirred at RT for $1 \mathrm{~h}$. The reaction mixture was then gravity filtered and the filtrate was left standing to allow crystallization of the complex. Solvent evaporation yielded brown- red colored crystals. Yield-390 mg, 95\%. ESI-MS: 556 $\left(\mathrm{M}^{+}-\mathrm{CF}_{3} \mathrm{SO}_{3}\right)$. Elemental analysis $=\mathrm{C}_{27} \mathrm{H}_{36} \mathrm{~N}_{4} \mathrm{O}_{9} \mathrm{~F}_{3} \mathrm{SMn}=704.59 \mathrm{~g} / \mathrm{mol}^{-1}$ Calculated: \%C 46.03, \%H 5.15, \%N 7.95, Found: \%C 45.84, \%H 5.32 \%N 8.07. IR (KBr, cm $\left.{ }^{-1}\right): 3437,3211$, 2929, 2865, 2360, 1599, 1454, 1379, 1260, 1220, 1028, 1147, 1043, 817 and 661.

Complex $\left[\mathrm{Mn}\left(4,6-\mathrm{diOMe}-\mathrm{sal}_{2} 323\right)\right] \mathrm{Cl} \cdot \mathrm{C}_{2} \mathrm{H}_{5} \mathrm{OH}$ (5). To a well stirred solution of $\mathrm{N} \mathrm{N}^{\prime}-$ bis(3-aminopropyl)ethylenediamine $(100 \mathrm{mg}, 0.574 \mathrm{mmol})$ in 1:1 ethanol:acetonitrile $(25 \mathrm{~mL})$ was added 4,6-dimethoxysalicylaldehyde $(209 \mathrm{mg}, 1.15 \mathrm{mmol})$ in 1:1 methanol:acetonitrile $(20 \mathrm{~mL})$. A yellow color developed, and the solution was stirred for $15 \mathrm{~min}$. Solid manganese(II) chloride tetrahydrate $(113.6 \mathrm{mg}, 0.574 \mathrm{mmol})$ was added to the reaction mixture and the resulting red-colored solution was stirred at RT for $1 \mathrm{~h}$ before being gravity filtered. The filtrate was dried by rotary evaporator and the resulting solute was redissolved in dichloromethane. This solution was then loaded onto a pre-prepared silica column and was eluted using a gradient increase in the polarity of the mobile phase by mixing dichloromethane with acetonitrile. The resultant eluted red solution was evaporated by rotary evaporation and the solute was redissolved in ethanol:acetonitrile (1:1) (25 mL). The filtrate was kept standing to enable the complex to crystallize. Solvent evaporation resulted in the formation of small single crystals with a red color and the structure was solved although a bulk sample could not be obtained.

\subsection{Synthesis and Characterisation of Complexes 6-9 with 4,6-diOMe-sal $2323-C_{n}$ Alkylated Ligands}

Ligands $\mathrm{H}_{2}$ (4,6-diOMe-sal ${ }_{2} 323-\mathrm{C}_{6}$ ), $\mathrm{H}_{2}$ (4,6-diOMe-sal $\left.{ }_{2} 323-\mathrm{C}_{12}\right), \mathrm{H}_{2}$ (4,6-diOMe-sal 2 323- $\left.\mathbf{C}_{18}\right)$ and $\mathbf{H}_{2}\left(4,6-\right.$ diOMe-sal $\left.{ }_{2} 323-C_{22}\right)$ were prepared using the general procedure below and used without further characterization, i.e., in an analogous fashion to the one-pot preparation of non-alkylated complexes 1-5 where the ligand was used as generated. In the general procedure neat 4,6-dimethoxysalicylaldehyde $(729 \mathrm{mg}, 4 \mathrm{mmol})$ was added to a solution of N,N'-bis(3-aminopropyl)ethylenediamine (348 mg, $2 \mathrm{mmol}$ ) in dry acetonitrile 
(25 $\mathrm{mL}$ ) and the reaction mixture stirred for $10 \mathrm{~min}$ by which time a bright yellow color indicated formation of the Schiff base. To this solution anhydrous potassium carbonate (552 $\mathrm{mg}, 4 \mathrm{mmol})$, anhydrous potassium iodide (664 mg, $4 \mathrm{mmol}$ ) and the appropriate 1bromoalkane ( $4 \mathrm{mmol})$ were added. The following masses of each bromoalkane were used: 1-bromohexane $\left(663.2 \mathrm{mg}, 4 \mathrm{mmol}\right.$, for $\mathrm{C}_{6}$-ligand), 1-bromododecane $(996 \mathrm{mg}, 4 \mathrm{mmol}$, for $\mathrm{C}_{12}$-ligand), 1-bromooctadodecane $\left(1.33 \mathrm{~g}, 4 \mathrm{mmol}\right.$, for $\mathrm{C}_{18}$-ligand), 1-bromodocosane $\left(1.56 \mathrm{~g}, 4 \mathrm{mmol}\right.$, for $\mathrm{C}_{22}$-ligand). In all cases the reaction mixture was then refluxed for $48 \mathrm{~h}$ in the presence of anhydrous sodium sulfate $(1 \mathrm{~g})$ and molecular sieves $(0.5 \mathrm{~g})$. The resulting brown colored reaction mixture was cooled to room temperature and the solvent removed under reduced pressure. A waxy brown solid was recovered in all four preparations and this was dissolved in chloroform $(50 \mathrm{~mL})$, washed with water $(50 \mathrm{~mL} \times 2)$ before the organic layer was dried over anhydrous sodium sulfate and the solvent removed under reduced pressure. A waxy brown solid was obtained in each case in crude yields of $95-97 \%$ and alkylation was confirmed by mass spectrometry: $\mathbf{H}_{\mathbf{2}}$ (4,6-diOMe-sal $\mathbf{2}_{\mathbf{2}} \mathbf{3 2 3}$ $\left.\mathrm{C}_{6}\right) \mathrm{ESI} / \mathrm{MS}=671\left(\mathrm{M}^{+}\right) ; \mathbf{H}_{2}$ (4,6-diOMe-sal $\left.{ }_{2} 323-\mathrm{C}_{12}\right) \mathrm{ESI} / \mathrm{MS}=723\left(\mathrm{M}^{+}\right) ; \mathbf{H}_{\mathbf{2}}$ (4,6-diOMesal $_{2}$ 323-C 18$)$ ESI $/ \mathrm{MS}=1010\left(\mathrm{M}^{+}\right) ; \mathbf{H}_{2}\left(\mathbf{4}, 6-\right.$ diOMe-sal $\left._{2} 323-\mathrm{C}_{22}\right) \mathrm{ESI} / \mathrm{MS}=1120\left(\mathrm{M}^{+}\right)$.

Complex $\left[\mathrm{Mn}\left(4,6-\mathrm{diOMe}-\mathrm{sal}_{2} 323-\mathrm{C}_{6}\right)\right]\left(\mathrm{BF}_{4}\right)_{0.8}\left(\mathrm{ClO}_{4}\right)_{0.2} \cdot 2 \mathrm{CH}_{3} \mathrm{OH}$ (6). To a well stirr-

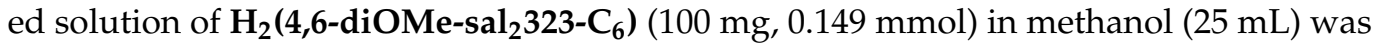
added manganese(II) perchlorate hexahydrate $(29.5 \mathrm{mg}, 0.08 \mathrm{mmol})$ and ammonium tetrafluoroborate $(15.6 \mathrm{mg}, 0.149 \mathrm{mmol})$. (Note: the addition of manganese(II) perchlorate was in error, the mass used was calculated for intended addition of $0.149 \mathrm{mmol}$ of manganese(II) chloride tetrahydrate but the perchlorate salt was used instead). The reaction mixture was allowed to stir for $6 \mathrm{~h}$ and filtered. Slow evaporation of the reaction mixture yielded green colored plate like crystals. ESI $/ \mathrm{MS}=723\left(\mathrm{M}^{+}\right)$. Elemental analysis: $\mathrm{C}_{40} \mathrm{H}_{68} \mathrm{~B}_{0.79} \mathrm{~N}_{4} \mathrm{O}_{8.82} \mathrm{~F}_{3.18} \mathrm{Cl}_{0.21} \mathrm{Mn}=877.56 \mathrm{~g} / \mathrm{mol}^{-1}$ Calculated: \%C 54.75, \%H 7.81, \%N 6.39, Found: \%C 55.30, \%H 7.35 \%N 6.77. IR (KBr, $\left.\mathrm{cm}^{-1}\right)$ : 3410, 2926, 2851, 2360, 1596, 1456, $1229,1122,1043,829$, and 673.

Complex $\left[\mathrm{Mn}\left(4,6-\mathrm{diOMe}-\mathrm{sal}_{2} 323-\mathrm{C}_{12}\right) \mathrm{BF}_{4}\right.$ (7). To a well stirred solution of $\mathbf{H}_{2}(\mathbf{4}, \mathbf{6}-$ diOMe-sal $\left.\mathbf{2}_{\mathbf{2}} \mathbf{3 2 3}-\mathrm{C}_{\mathbf{1 2}}\right)(100 \mathrm{mg}, 0.119 \mathrm{mmol})$ in methanol $(25 \mathrm{~mL})$ was added manganese(II) chloride tetrahydrate $(23.55 \mathrm{mg}, 0.119 \mathrm{mmol})$ and ammonium tetrafluoroborate $(12.45 \mathrm{mg}$, $0.119 \mathrm{mmol})$. The reaction mixture was allowed to stir for $6 \mathrm{~h}$ and filtered. Slow evaporation of the solvent at room temperature yielded green colored plate like crystals. Yield-91 mg, $78 \%$. ESI $/ \mathrm{MS}=893\left(\mathrm{M}^{+}\right)$. Elemental analysis: $\mathrm{C}_{50} \mathrm{H}_{84} \mathrm{~N}_{4} \mathrm{O}_{10} \mathrm{ClMn}=991.63 \mathrm{~g} / \mathrm{mol}^{-1}$ Calculated: \%C 60.56, \%H 8.54, \%N 5.65, Found: \%C 60.57, \%H 8.57 \%N 5.61. IR (KBr, $\left.\mathrm{cm}^{-1}\right)$ : 3428, 3924, 2853, 2360, 1596, 1458, 1375, 1229, 1160, 1123, 1054, 860, 804, 761 and 672.

Complex $\left[\mathrm{Mn}\left(4,6-\mathrm{diOMe}-\mathrm{sal}_{2} 323-\mathrm{C}_{18}\right) \mathrm{BF}_{4}(\mathbf{8})\right.$. To a well stirred solution of $\mathbf{H}_{2}(\mathbf{4}, \mathbf{6}-$ diOMe-sal $\left.{ }_{2} 323-C_{18}\right)(100 \mathrm{mg}, 0.099 \mathrm{mmol})$ in methanol $(25 \mathrm{~mL})$ was added manganese(II) chloride tetrahydrate $(19.7 \mathrm{mg}, 0.099 \mathrm{mmol})$ and ammonium tetrafluoroborate $(10.6 \mathrm{mg}$, $0.099 \mathrm{mmol})$. The reaction mixture was allowed to stir for $6 \mathrm{~h}$ and filtered. After $16 \mathrm{~h}$ a red-colored solid together with yellow-colored traces of unreacted Schiff base were isolated which were purified by column chromatotography by elution with $\mathrm{CHCl}_{3}$ and $1 \% \mathrm{MeOH} / \mathrm{CHCl}_{3}$. Yield: $48 \mathrm{mg}$, 42\%. ESI/MS = $1063\left(\mathrm{M}^{+}\right)$. Elemental analysis: $\mathrm{C}_{62} \mathrm{H}_{108} \mathrm{BF}_{4}$ $\mathrm{MnN}_{4} \mathrm{O}_{6}=1147.31 \mathrm{~g} / \mathrm{mol}^{-1}$. Calculated: \%C 64.91, \%H 9.49, \%N 4.88, Found: \%C 64.16, \%H 9.52 \%N 4.88. IR (KBr, cm $\left.{ }^{-1}\right)$ : 3450, 3211, 2923, 2852, 2282, 1596, 1460, 1376, 1230, 1162, $1123,1055,859,804,762$ and 672 .

Complex $\left[\mathrm{Mn}\left(4,6-\mathrm{diOMe}-\mathrm{sal}_{2} \mathbf{3 2 3}_{2}-\mathrm{C}_{22}\right) \mathrm{BF}_{4}\right.$ (9). To a well stirred solution of $\mathbf{H}_{\mathbf{2}}(\mathbf{4}, \mathbf{6}-$ diOMe-sal $\left.{ }_{2} 323-C_{22}\right)(100 \mathrm{mg}, 0.089 \mathrm{mmol})$ in methanol $(25 \mathrm{~mL})$ was added manganese(II) chloride tetrahydrate $(19.7 \mathrm{mg}, 0.099 \mathrm{mmol})$ and ammonium tetrafluoroborate $(10.6 \mathrm{mg}$, $0.099 \mathrm{mmol})$. The reaction mixture was allowed to stir for $6 \mathrm{~h}$ and filtered. Slow evaporation of the reaction mixture yielded ruby-red colored crystals. Yield-56 mg, 49\%. ESI $/ \mathrm{MS}=1173\left(\mathrm{M}^{+}\right)$. Elemental analysis: $\mathrm{C}_{70} \mathrm{H}_{124} \mathrm{BF}_{4} \mathrm{MnN}_{4} \mathrm{O}_{6}=1259.49 \mathrm{~g} / \mathrm{mol}^{-1}$ Calculated: \%C 66.75, \%H 9.92, \%N 4.45, Found: \%C 66.75, \%H 9.96 \%N 4.43. IR (KBr, $\left.\mathrm{cm}^{-1}\right)$ : 3397, 3211, 2921, 2850, 2365, 1595, 1459, 1375, 1229, 1161, 1122, 1049, 861, 802, 722 and 672. 


\subsection{Synthesis and Characterisation of Complexes 10-12 with 3-OMe-sal ${ }_{2} 323-C_{n}$ Alkylated Ligands}

Ligands $\mathrm{H}_{2}$ (3-OMe--sal $\left.{ }_{2} 323-\mathrm{C}_{6}\right), \mathrm{H}_{2}$ (3-OMe-sal $\left.{ }_{2} 323-\mathrm{C}_{12}\right)$ and $\mathrm{H}_{2}\left(4,6-\right.$ diOMe-sal $_{2} 323-$ $\mathrm{C}_{18}$ ) were prepared using a slightly modified procedure to that used for the $\mathbf{H}_{\mathbf{2}}(\mathbf{4}, \mathbf{6}$-diOMesal $\left._{2} 323-\mathrm{C}_{n}\right)$ ligands. As was the case for the 4,6-diOMe-sal $2323-\mathrm{C}_{n}$ complexes, the $\mathrm{H}_{2}(3-$ OMe-sal ${ }_{2} 323-C_{n}$ ), ligands were also used without further characterization, i.e., in an analogous fashion to the one-pot preparation of non-alkylated complexes 1-5 where the ligand was used as generated.

In a typical procedure 3-methoxysalicylaldehyde $(0.609 \mathrm{~g}, 4 \mathrm{mmol})$ was added to a solution of 1,2-bis(3-aminopropylamino)ethane $(0.349 \mathrm{~g}, 2 \mathrm{mmol})$ in dry acetonitrile $(50 \mathrm{~mL})$. After $15 \mathrm{~min}$ molecular sieves and anhydrous potassium carbonate $(0.552 \mathrm{~g}, 4 \mathrm{mmol})$ were added. The reaction mixture was stirred for $10 \mathrm{~min}$ after which the appropriate 1-bromoalkane $(4 \mathrm{mmol})$ and potassium iodide $(0.662 \mathrm{~g}, 4 \mathrm{mmol})$ were added and the suspension was refluxed for $48 \mathrm{~h}$. The reaction mixture was filtered and the solvent removed under reduced pressure. The resulting oil was dissolved in dichloromethane and washed with brine and the organic fraction was dried with anhydrous sodium sulfate to obtain the alkylated ligand as a bright yellow oil. In all cases, this was directly used for complexation to yield complexes 10-12 which were characterized by single crystal diffraction, elemental analysis and mass spectrometry.

Complex [Mn(3-OMe-sal $\left.\left.{ }_{2} 323-\mathrm{C}_{6}\right)\right] \mathrm{PF}_{6}(\mathbf{1 0})$. Ligand $\mathbf{H}_{2}\left(3-\mathrm{OMe}-\mathrm{sal}_{2} 323-\mathrm{C}_{6}\right)(1.222 \mathrm{~g}$, $2 \mathrm{mmol}$ ) was dissolved in methanol $(30 \mathrm{~mL})$ and was kept aside in one beaker and in a separate beaker manganese(II) chloride tetrahydrate $(0.396 \mathrm{~g}, 2 \mathrm{mmol})$ was dissolved in methanol $(20 \mathrm{~mL})$ to which ammonium hexafluorophosphate $(0.326 \mathrm{~g}, 2 \mathrm{mmol})$ was added. The pink methanolic metal salt solution was then added to the yellow ligand solution giving a deep brown solution that was stirred at room temperature for $30 \mathrm{~min}$. The solvent was evaporated, and the resulting brown oil was dissolved in dichloromethane $(10 \mathrm{~mL})$ and the desired product was purified by filtration over a bed of silica using dichloromethane to elute the product. The dichloromethane was removed under reduced pressure to yield a brown oil that was recrystallized from methanol. The solvent was evaporated slowly at room temperature and after 4 days black crystalline needles were obtained. Yield- $658 \mathrm{mg}$, $41 \%$. Elemental analysis: $\mathrm{C}_{36} \mathrm{H}_{56} \mathrm{PF}_{6} \mathrm{~N}_{4} \mathrm{O}_{4} \mathrm{Mn}=808.76 \mathrm{~g} / \mathrm{mol}^{-1}$ Calculated: $\% \mathrm{C} 53.46, \% \mathrm{H}$ 6.98, \%N 6.93, Found: \%C 53.85, \%H 6.99 \%N 6.64. IR (KBr, cm $\left.{ }^{-1}\right): 2954,2930,2870,1623$, $1598,1557,1471,1457,1446,1393,1283,1254,1223,1086,843,751,740,637,558,459,353$, 234, 222.

Complex [Mn(3-OMe-sal $\left.\left.{ }_{2} 323-\mathrm{C}_{12}\right)\right] \mathrm{PF}_{6} \cdot \mathrm{CH}_{3} \mathrm{CN}$ (11). Ligand $\mathrm{H}_{2}\left(3-\mathrm{OMe}-\mathrm{sal}_{2} 323-\mathrm{C}_{12}\right)$ $(3.116 \mathrm{~g}, 4 \mathrm{mmol})$ was dissolved in methanol $(30 \mathrm{~mL})$ and was kept aside in one beaker and in a separate beaker manganese(II) chloride tetrahydrate $(0.792 \mathrm{~g}, 4 \mathrm{mmol})$ was dissolved in methanol $(20 \mathrm{~mL})$ to which ammonium hexafluorophosphate $(0.652 \mathrm{~g}, 4 \mathrm{mmol})$ was added. The pink methanolic metal salt solution was then added to the yellow ligand solution giving a deep brown solution that was stirred at room temperature for $30 \mathrm{~min}$. The solvent was evaporated and the resulting brown oil was dissolved in dichloromethane $(10 \mathrm{~mL})$ and the desired product was purified by filtration over a bed of silica using dichloromethane to elute the product. The dichloromethane was removed under reduced pressure to yield a brown oil that was recrystallized from methanol. The solvent was evaporated slowly at room temperature and after 5 days black crystals were obtained. Yield- $1.274 \mathrm{~g}, 33 \%$. Elemental analysis: $\mathrm{C}_{50} \mathrm{H}_{83} \mathrm{~N}_{5} \mathrm{O}_{4} \mathrm{~F}_{6} \mathrm{PMn}=1018.39 \mathrm{~g} / \mathrm{mol}^{-1}$ Calculated: $\% \mathrm{C} 58.98, \% \mathrm{H} 8.22$, \%N 6.88, Found: \%C 58.78, \%H 8.17 \%N 6.10. IR (KBr, cm $\left.{ }^{-1}\right)$ : 2924, 2853, 1657, 1613, 1597, $1557,1473,1449,1398,1289,1253,1222,1169,1081,1037,969,955,844,784,749,720,643$, $558,458,359,231,222$.

Complex [Mn(3-OMe-sal $\left.\left.{ }_{2} 323-\mathrm{C}_{18}\right)\right] \mathrm{PF}_{6} \cdot \mathrm{CH}_{2} \mathrm{Cl}_{2}$ (12). Ligand $\mathrm{H}_{2}$ (3-OMe-sal $2323-\mathrm{C}_{18}$ ) $(3.790 \mathrm{~g}, 4 \mathrm{mmol})$ was dissolved in methanol $(30 \mathrm{~mL})$ and was kept aside in one beaker and in a separate beaker manganese(II) chloride tetrahydrate $(0.792 \mathrm{~g}, 4 \mathrm{mmol})$ was dissolved in methanol $(20 \mathrm{~mL})$ to which ammonium hexafluorophosphate $(0.652 \mathrm{~g}, 4 \mathrm{mmol})$ was added. The pink methanolic metal salt solution was then added to the yellow ligand solution giving a deep brown solution that was stirred at room temperature for $30 \mathrm{~min}$. The solvent 
was evaporated, and the resulting brown oil was dissolved in dichloromethane $(10 \mathrm{~mL})$ and the desired product was purified by filtration over a bed of silica using dichloromethane to elute the product. The dichloromethane was removed under reduced pressure to yield a brown oil that was recrystallized from methanol. The solvent was evaporated slowly at room temperature and after 5 days black powder was obtained. Yield-911 mg, 20\%. Elemental analysis: $\mathrm{C}_{61} \mathrm{H}_{106} \mathrm{~N}_{4} \mathrm{O}_{4} \mathrm{~F}_{6} \mathrm{PCl}_{2} \mathrm{Mn}=1230.35 \mathrm{~g} / \mathrm{mol}^{-1}$ Calculated: $\% \mathrm{C} 59.55, \% \mathrm{H}$ 8.68, \%N 4.55, Found: \%C 62.06, \%H 8.94 \%N 4.51. IR (KBr, $\left.\mathrm{cm}^{-1}\right): 2926,2851,1657,1617$, $1597,1559,1469,1449,1394,1283,1252,1223,1172,1086,1040,952,846,775,741,720,640$, $557,458,355,282,248,226$.

Supplementary Materials: The following supporting information can be downloaded at: https: / / www.mdpi.com/article/10.3390/magnetochemistry8010008/s1, Figure S1: C6-Alkylated complex 6 viewed along b-axis, Figure S2: C12-Alkylated complex 7 viewed along the b-axis, Figure S3: $\mathrm{C}_{6}$-Alkylated complex 10 viewed along the c-axis, Figure S4: $\mathrm{C}_{12}$-Alkylated complex 11 viewed along the a-axis, Table S1: Crystallographic details for compounds 1-3, Table S2: Crystallographic details for compounds 4 \& 5, Table S3: Crystallographic details for compounds 6 \& 7, Table S4: Crystallographic details for compounds 10-12, Table S5: Raman vibration modes of complexes (10)-(12) collected at room temperature.

Author Contributions: Conceptualization, G.G.M.; methodology, K.P., P.N.M., T.L., S.S. and A.S.; formal analysis, A.B.C., K.P., T.L. and P.N.M.; data curation, A.B.C., T.E.K. and G.G.M.; magnetic data collection and analysis, B.G. and A.B.C.; visualization, A.B.C.; crystallographic collection and solving, H.M.-B.; writing—original draft preparation, A.B.C. and G.G.M.; writing-review and editing, A.B.C. and G.G.M.; supervision, T.E.K. and G.G.M.; funding acquisition, G.G.M. All authors have read and agreed to the published version of the manuscript.

Funding: We thank Science Foundation Ireland for generous support via US-Ireland (SFI 19/US/3631) and Frontiers for the Future (SFI 19/FFP/6909) Awards (G.G.M., A.S., A.B.C.). We also thank the Irish Research Council for Science Engineering and Technology (IRCSET) for the award of Government of Ireland Research Scholarships (to K.P. and B.G.) and to P.N.M. via the EU ERAChemistry programme. P.N.M. also thanks the Portuguese Foundation for Science and Technology (FTC) for the program CEECIND/00509/2017. All authors gratefully acknowledge significant funding for a SQUID magnetometer from the Irish Higher Education Authority.

Institutional Review Board Statement: Not applicable.

Informed Consent Statement: Not applicable.

Data Availability Statement: Crystallographic data for the structures reported in this paper have been deposited with the Cambridge Crystallographic Data Centre at https:/ / www.ccdc.cam.ac.uk/ as supplementary publication numbers CCDC-2124577-2124586.

Conflicts of Interest: The authors declare no conflict of interest.

\section{References}

1. Murray, K.S.; Kepert, C.J. Cooperativity in spin crossover systems: Memory, magnetism and microporosity. In Spin Crossover in Transition Metal Compounds I; Gütlich, P., Goodwin, H.A., Eds.; Springer: Berlin/Heidelberg, Germany, 2004; pp. 195-228. [CrossRef]

2. Hogue, R.W.; Singh, S.; Brooker, S. Spin crossover in discrete polynuclear Iron(II) complexes. Chem. Soc. Rev. 2018, 47, 7303-7338. [CrossRef]

3. Ni, Z.-P.; Liu, J.-L.; Hoque, M.N.; Liu, W.; Li, J.-Y.; Chen, Y.-C.; Tong, M.-L. Recent advances in guest effects on spin-crossover behavior in Hofmann-type metal-organic frameworks. Coord. Chem. Rev. 2017, 335, 28-43. [CrossRef]

4. Barker, A.; Kelly, C.T.; Kühne, I.A.; Hill, S.; Krzystek, J.; Wix, P.; Esien, K.; Felton, S.; Müller-Bunz, H.; Morgan, G.G. Spin state solvomorphism in a series of rare $S=1$ manganese(III) complexes. Dalton Trans. 2019, 48, 15560-15566. [CrossRef]

5. Banerjee, H.; Chakraborty, S.; Saha-Dasgupta, T. Design and control of cooperativity in spin-crossover in metal-organic complexes: A theoretical overview. Inorganics 2017, 5, 47. [CrossRef]

6. $\quad$ Busch, R.; Carter, A.B.; Konidaris, K.F.; Kühne, I.A.; González, R.; Anson, C.E.; Powell, A.K. The first use of a ReX 5 synthon to modulate Fe $\mathrm{FII}^{\mathrm{II}}$ spin crossover via supramolecular halogen $\cdots$ Halogen Interactions. Chemistry 2020, 26, 11835-11840. [CrossRef]

7. Pandurangan, K.; Gildea, B.; Murray, C.; Harding, C.J.; Müller-Bunz, H.; Morgan, G.G. Lattice effects on the spin-crossover profile of a mononuclear Manganese(III) cation. Chemistry 2012, 18, 2021-2029. [CrossRef] 
8. Gildea, B.; Harris, M.M.; Gavin, L.C.; Murray, C.A.; Ortin, Y.; Müller-Bunz, H.; Harding, C.J.; Lan, Y.; Powell, A.K.; Morgan, G.G. Substituent effects on spin state in a series of mononuclear Manganese(III) complexes with hexadentate schiff-base ligands. Inorg. Chem. 2014, 53, 6022-6033. [CrossRef] [PubMed]

9. Kühne, I.A.; Gavin, L.C.; Harris, M.; Gildea, B.; Müller-Bunz, H.; Stein, M.; Morgan, G.G. Mn(III) complexes with nitro-substituted ligands-Spin states with a twist. J. Appl. Phys. 2021, 129, 213903. [CrossRef]

10. Gildea, B.; Gavin, L.C.; Murray, C.A.; Müller-Bunz, H.; Harding, C.J.; Morgan, G.G. Supramolecular modulation of spin crossover profile in manganese(III). Supramol. Chem. 2012, 24, 641-653. [CrossRef]

11. Kühne, I.A.; Esien, K.; Gavin, L.C.; Müller-Bunz, H.; Felton, S.; Morgan, G.G. Modulation of $\mathrm{Mn}^{3+}$ spin state by guest molecule inclusion. Molecules 2020, 25, 5603. [CrossRef] [PubMed]

12. Kühne, I.A.; Barker, A.; Zhang, F.; Stamenov, P.; O’Doherty, O.; Müller-Bunz, H.; Stein, M.; Rodriguez, B.J.; Morgan, G.G. Modulation of Jahn-Teller distortion and electromechanical response in a $\mathrm{Mn}^{3+}$ spin crossover complex. J. Phys. Condens. Matter 2020, 32, 404002. [CrossRef]

13. Harding, D.J.; Harding, P.; Phonsri, W. Spin crossover in Iron(III) complexes. Coord. Chem. Rev. 2016, 313, 38-61. [CrossRef]

14. Halcrow, M.A. Structure: Function relationships in molecular spin-crossover complexes. Chem. Soc. Rev. 2011, 40, 4119-4142. [CrossRef] [PubMed]

15. Tweedle, M.F.; Wilson, L.J. Variable spin Iron(III) chelates with hexadentate ligands derived from triethylenetetramine and various salicylaldehydes. Synthesis, characterization, and solution state studies of a new 2T.dblarw. 6A spin equilibrium system. J. Am. Chem. Soc. 1976, 98, 4824-4834. [CrossRef]

16. Conti, A.J.; Chadha, R.K.; Sena, K.M.; Rheingold, A.L.; Hendrickson, D.N. Dynamics and phase transitions in spin-crossover complexes: X-ray structures and basic crossover phenomena in the solvate series bis(3-ethoxysalicylideneaziridinopropylaminato)iron perchlorate.solvate. Inorg. Chem. 1993, 32, 2670-2680. [CrossRef]

17. Real, J.A.; Gaspar, A.B.; Niel, V.; Muñoz, M.C. Communication between Iron(II) building blocks in cooperative spin transition phenomena. Coord. Chem. Rev. 2003, 236, 121-141. [CrossRef]

18. Hostettler, M.; Törnroos, K.W.; Chernyshov, D.; Vangdal, B.; Bürgi, H.-B. Challenges in engineering spin crossover: Structures and magnetic properties of six alcohol solvates of Iron(II) Tris(2-picolylamine) dichloride. Angew. Chem. Int. Ed. 2004, 43, 4589-4594 [CrossRef]

19. Quesada, M.; Prins, F.; Bill, E.; Kooijman, H.; Gamez, P.; Roubeau, O.; Spek, A.L.; Haasnoot, J.G.; Reedijk, J. Counterion effect on the spin-transition properties of the cation $[\mathrm{Fe}(\mathrm{btzx}) 3] 2+(\mathrm{btzx}=\mathrm{m}-\mathrm{X} y l y l e n e b i s(t e t r a z o l e))$. Chemistry 2008, 14, 8486-8499. [CrossRef]

20. Yamada, M.; Hagiwara, H.; Torigoe, H.; Matsumoto, N.; Kojima, M.; Dahan, F.; Tuchagues, J.-P.; Re, N.; Iijima, S. A variety of spin-

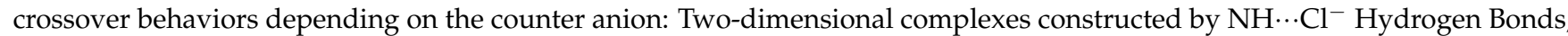
$\left[\mathrm{Fe}^{\mathrm{II}} \mathrm{H}_{3} \mathrm{~L}^{\mathrm{Me}}\right] \mathrm{Cl} \cdot \mathrm{X}\left(\mathrm{X}=\mathrm{PF}_{6}{ }^{-}, \mathrm{AsF}_{6}{ }^{-}, \mathrm{SbF}_{6}{ }^{-}, \mathrm{CF}_{3} \mathrm{SO}_{3}{ }^{-} ; \mathrm{H}_{3} \mathrm{~L}^{\mathrm{Me}}=\right.$ Tris[2 - $\{[(2-$ methylimidazol-4-yl)methylidene $]$ amino $\}$ ethyl $]$ amine $)$. Chemistry 2006, 12, 4536-4549. [CrossRef]

21. Halcrow, M.A. Iron(II) complexes of 2,6-di(pyrazol-1-yl)pyridines-A versatile system for spin-crossover research. Coord. Chem. Rev. 2009, 253, 2493-2514. [CrossRef]

22. Scott, H.S.; Staniland, R.W.; Kruger, P.E. Spin crossover in homoleptic Fe(II) imidazolylimine complexes. Coord. Chem. Rev. 2018, 362, 24-43. [CrossRef]

23. Xue, S.; Rotaru, A.; Garcia, Y. Ligand field strength tuning in the model $\left[\mathrm{Fe}\left(\mathrm{H}_{2} \mathrm{Bpz}_{2}\right)_{2}\right.$ (bipy)] spin crossover complex. Hyperfine Interact. 2019, 240, 91. [CrossRef]

24. Boča, R.; Renz, F.; Boča, M.; Fuess, H.; Haase, W.; Kickelbick, G.; Linert, W.; Vrbová-Schikora, M. Tuning the spin crossover above room temperature: Iron(II) complexes of substituted and deprotonated 2,6-bis(benzimidazol-2-yl)pyridine. Inorg. Chem. Commun. 2005, 8, 227-230. [CrossRef]

25. Deorukhkar, N.; Besnard, C.; Guénée, L.; Piguet, C. Tuning spin-crossover transition temperatures in non-symmetrical homoleptic meridional/facial $\left[\mathrm{Fe}\left(\text { didentate) }{ }_{3}\right]^{2+}\right.$ complexes: What for and who cares about it? Dalton Trans. 2021, 50, 1206-1223. [CrossRef] [PubMed]

26. Palion-Gazda, J.; Machura, B.; Kruszynski, R.; Grancha, T.; Moliner, N.; Lloret, F.; Julve, M. Spin crossover in double salts containing six- and four-coordinate Cobalt(II) ions. Inorg. Chem. 2017, 56, 6281-6296. [CrossRef] [PubMed]

27. Galet, A.; Gaspar, A.B.; Muñoz, M.C.; Real, J.A. Influence of the counterion and the solvent molecules in the spin crossover system [Co(4-terpyridone)2] Xp·nH ${ }_{2} \mathrm{O}$. Inorg. Chem. 2006, 45, 4413-4422. [CrossRef] [PubMed]

28. Palion-Gazda, J.; Świtlicka-Olszewska, A.; Machura, B.; Grancha, T.; Pardo, E.; Lloret, F.; Julve, M. High-temperature spin crossover in a mononuclear six-coordinate Cobalt(II) complex. Inorg. Chem. 2014, 53, 10009-10011. [CrossRef]

29. Judge, J.S.; Baker, W.A. Magnetic and spectral studies of some anomolous Mono-(2,2' ,2",-terpyridine) complexes of Co(II) and $\mathrm{Ni}(\mathrm{II})$. Inorg. Chim. Acta 1967, 1, 245-248. [CrossRef]

30. Weber, B.; Bauer, W.; Obel, J. An Iron(II) spin-crossover complex with a $70 \mathrm{~K}$ wide thermal hysteresis loop. Angew. Chem. Int. Ed. 2008, 47, 10098-10101. [CrossRef]

31. Weber, B.; Obel, J.; Henner-Vásquez, D.; Bauer, W. Two new Iron(II) spin-crossover complexes with $\mathrm{N}_{4} \mathrm{O}_{2}$ coordination sphere and spin transition around room temperature. Eur. J. Inorg. Chem. 2009, 2009, 5527-5534. [CrossRef]

32. Li, B.; Wei, R.-J.; Tao, J.; Huang, R.-B.; Zheng, L.-S.; Zheng, Z. Solvent-Induced transformation of single crystals of a spin-crossover (SCO) compound to single crystals with two distinct SCO centers. J. Am. Chem. Soc. 2010, 132, 1558-1566. [CrossRef] 
33. Halcrow, M.A.; Capel Berdiell, I.; Pask, C.M.; Kulmaczewski, R. Relationship between the molecular structure and switching temperature in a library of spin-crossover molecular materials. Inorg. Chem. 2019, 58, 9811-9821. [CrossRef]

34. Létard, J.-F.; Guionneau, P.; Codjovi, E.; Lavastre, O.; Bravic, G.; Chasseau, D.; Kahn, O. Wide thermal hysteresis for the mononuclear spin-crossover compound cis-bis(thiocyanato)bis[ $\mathrm{N}-\left(2^{\prime}\right.$-pyridylmethylene)-4-(phenylethynyl)anilino]Iron(II). J. Am. Chem. Soc. 1997, 119, 10861-10862. [CrossRef]

35. Hagiwara, H.; Hashimoto, S.; Matsumoto, N.; Iijima, S. Two-dimensional Iron(II) spin crossover complex constructed of bifurcated $\mathrm{NH} \cdots \mathrm{O}^{-}$hydrogen bonds and $\pi-\pi$ interactions: $\left[\mathrm{Fe}^{\mathrm{II}}\left(\mathrm{HL}^{\mathrm{H}, \mathrm{Me}}\right)_{2}\right]\left(\mathrm{ClO}_{4}\right)_{2} \cdot 1.5 \mathrm{MeCN}\left(\mathrm{HL}^{\mathrm{H}, \mathrm{Me}}=\right.$ Imidazol-4-yl-methylidene-8amino-2-methylquinoline). Inorg. Chem. 2007, 46, 3136-3143. [CrossRef] [PubMed]

36. Zhong, Z.J.; Tao, J.-Q.; Yu, Z.; Dun, C.-Y.; Liu, Y.-J.; You, X.-Z. A stacking spin-crossover Iron(II) compound with a large hysteresis. J. Chem. Soc. Dalton Trans. 1998, 327-328. [CrossRef]

37. Pfaffeneder, T.M.; Thallmair, S.; Bauer, W.; Weber, B. Complete and incomplete spin transitions in 1D chain Iron(II) compounds. New J. Chem. 2011, 35, 691-700. [CrossRef]

38. Zhang, W.; Zhao, F.; Liu, T.; Yuan, M.; Wang, Z.-M.; Gao, S. Spin crossover in a Series of Iron(II) complexes of 2-(2-Alkyl-2Htetrazol-5-yl)-1,10-phenanthroline: Effects of alkyl side chain, solvent, and anion. Inorg. Chem. 2007, 46, 2541-2555. [CrossRef]

39. Hayami, S.; Danjobara, K.; Shigeyoshi, Y.; Inoue, K.; Ogawa, Y.; Maeda, Y. Crystal structure and mesogenic property of an Iron(II) complex with a terpyridine derivative ligand. Inorg. Chem. Commun. 2005, 8, 506-509. [CrossRef]

40. Scott, H.S.; Moubaraki, B.; Paradis, N.; Chastanet, G.; Létard, J.-F.; Batten, S.R.; Murray, K.S. 2,2'-Dipyridylamino-based ligands with substituted alkyl chain groups and their mononuclear-M(II) spin crossover complexes. J. Mater. Chem. C 2015, 3, 7845-7857. [CrossRef]

41. Ueno, S.; Kawasaki, T.; Okabayashi, J.; Kitazawa, T. 2D spin-crossover coordination polymer Fe(hexyl-nicotinate $)_{2}\left[\mathrm{Au}(\mathrm{CN})_{2}\right]_{2}$ Bull. Chem. Soc. Jpn. 2016, 89, 581-583. [CrossRef]

42. Seredyuk, M.; Gaspar, A.B.; Ksenofontov, V.; Galyametdinov, Y.; Kusz, J.; Gütlich, P. Does the solid-liquid crystal phase transition provoke the spin-state change in spin-crossover metallomesogens? J. Am. Chem. Soc. 2008, 130, 1431-1439. [CrossRef]

43. Seredyuk, M. Iron(II) metallomesogens based on symmetrical tripod ligands. Inorg. Chim. Acta 2012, 380, 65-71. [CrossRef]

44. Seredyuk, M.; Gaspar, A.B.; Ksenofontov, V.; Galyametdinov, Y.; Kusz, J.; Gütlich, P. Iron(II) metallomesogens exhibiting coupled spin state and liquid crystal phase transitions near room temperature. Adv. Funct. Mater. 2008, 18, 2089-2101. [CrossRef]

45. Vologzhanina, A.V.; Belov, A.S.; Novikov, V.V.; Dolganov, A.V.; Romanenko, G.V.; Ovcharenko, V.I.; Korlyukov, A.A.; Buzin, M.I.; Voloshin, Y.Z. Synthesis and temperature-induced structural phase and spin transitions in hexadecylboron-capped Cobalt(II) hexachloroclathrochelate and its diamagnetic Iron(II)-encapsulating analogue. Inorg. Chem. 2015, 54, 5827-5838. [CrossRef] [PubMed]

46. Voloshin, Y.Z.; Varzatskii, O.A.; Stash, A.I.; Belsky, V.K.; Bubnov, Y.N.; Vorontsov, I.I.; Potekhin, K.A.; Antipin, M.Y.; Polshin, E.V. Template synthesis, structure and unusual series of phase transitions in clathrochelate Iron(II) $\alpha$-dioximates and oximehydrazonates formed by capping with functionalized boron-containing agents. Polyhedron 2001, 20, 2721-2733. [CrossRef]

47. Han, W.-K.; Li, Z.-H.; Zhu, W.; Li, T.; Li, Z.; Ren, X.; Gu, Z.-G. Molecular isomerism induced Fe(II) spin state difference based on the tautomerization of the 4(5)-methylimidazole group. Dalton Trans. 2017, 46, 4218-4224. [CrossRef]

48. Kitchen, J.A.; White, N.G.; Jameson, G.N.L.; Tallon, J.L.; Brooker, S. Effect of counteranion X on the spin crossover properties of a family of Diiron(II) triazole complexes [Fe $\left.{ }_{2}{ }_{2}(\mathrm{PMAT})_{2}\right](\mathrm{X})_{4}$. Inorg. Chem. 2011, 50, 4586-4597. [CrossRef]

49. Schlamp, S.; Weber, B.; Naik, A.D.; Garcia, Y. Cooperative spin transition in a lipid layer like system. Chem. Commun. 2011, 47, 7152-7154. [CrossRef] [PubMed]

50. Schlamp, S.; Thoma, P.; Weber, B. New octahedral, head-tail Iron(II) complexes with spin crossover properties. Eur. J. Inorg. Chem. 2012, 2012, 2759-2768. [CrossRef]

51. Schlamp, S.; Dankhoff, K.; Weber, B. Amphiphilic Iron(II) complexes with short alkyl chains-crystal packing and spin transition properties. New J. Chem. 2014, 38, 1965-1972. [CrossRef]

52. Schlamp, S.; Lochenie, C.; Bauer, T.; Kempe, R.; Weber, B. Iron(II) spin-crossover complexes with schiff base like ligands and $N$-alkylimidazoles. Eur. J. Inorg. Chem. 2015, 2015, 408-413. [CrossRef]

53. Schlamp, S.; Thoma, P.; Weber, B. Influence of the alkyl chain length on the self-assembly of amphiphilic iron complexes: An analysis of X-ray structures. Chemistry 2014, 20, 6462-6473. [CrossRef]

54. Martinho, P.N.; Ortin, Y.; Gildea, B.; Gandolfi, C.; McKerr, G.; O’Hagan, B.; Albrecht, M.; Morgan, G.G. Inducing hysteretic spin crossover in solution. Dalton Trans. 2012, 41, 7461-7463. [CrossRef] [PubMed]

55. Martinho, P.N.; Kühne, I.A.; Gildea, B.; McKerr, G.; O’Hagan, B.; Keyes, T.E.; Lemma, T.; Gandolfi, C.; Albrecht, M.; Morgan, G.G. Self-assembly properties of amphiphilic Iron(III) spin crossover complexes in water and at the air-water interface. Magnetochemistry 2018, 4, 49. [CrossRef]

56. Gandolfi, C.; Moitzi, C.; Schurtenberger, P.; Morgan, G.G.; Albrecht, M. Improved cooperativity of spin-labile iron(III) centers by self-assembly in solution. J. Am. Chem. Soc. 2008, 130, 14434-14435. [CrossRef] [PubMed]

57. Gandolfi, C.; Morgan, G.G.; Albrecht, M. A magnetic iron(III) switch with controlled and adjustable thermal response for solution processing. Dalton Trans. 2012, 41, 3726-3730. [CrossRef] [PubMed]

58. Martinho, P.N.; Harding, C.J.; Müller-Bunz, H.; Albrecht, M.; Morgan, G.G. Inducing spin crossover in amphiphilic iron(III) complexes. Eur. J. Inorg. Chem. 2010, 2010, 675-679. [CrossRef] 
59. Gandolfi, C.; Miyashita, N.; Kurth, D.G.; Martinho, P.N.; Morgan, G.G.; Albrecht, M. Organization of spin- and redox-labile metal centers into Langmuir and Langmuir-Blodgett films. Dalton Trans. 2010, 39, 4508-4516. [CrossRef]

60. Nakaya, M.; Shimayama, K.; Takami, K.; Hirata, K.; Amolegbe, S.A.; Nakamura, M.; Lindoy, L.F.; Hayami, S. Structures and magnetic properties of Iron(III) complexes with long alkyl chains. Crystals 2014, 4, 104. [CrossRef]

61. Martinho, P.N.; Lemma, T.; Gildea, B.; Picardi, G.; Müller-Bunz, H.; Forster, R.J.; Keyes, T.E.; Redmond, G.; Morgan, G.G. Template assembly of spin crossover one-dimensional nanowires. Angew. Chem. Int. Ed. 2012, 51, 11995-11999. [CrossRef]

62. Johnson, C.J.; Morgan, G.G.; Albrecht, M. Predictable adjustment of spin crossover temperature in solutions of Iron(III) complexes functionalized with alkyl-urea tails. J. Mater. Chem. C 2015, 3, 7883-7889. [CrossRef]

63. Fitzpatrick, A.J.; Martinho, P.N.; Gildea, B.J.; Holbrey, J.D.; Morgan, G.G. Robust room temperature hysteresis in an Fe ${ }^{\mathrm{III}}$ spin crossover metallomesogen. Eur. J. Inorg. Chem. 2016, 2016, 2025-2029. [CrossRef]

64. Gandolfi, C.; Cotting, T.; Martinho, P.N.; Sereda, O.; Neels, A.; Morgan, G.G.; Albrecht, M. Synthesis and self-assembly of spin-labile and redox-active Manganese(III) complexes. Dalton Trans. 2011, 40, 1855-1865. [CrossRef] [PubMed]

65. Carter, A.B.; Laverick, R.J.; Wales, D.J.; Akponasa, S.O.; Scott, A.J.; Keene, T.D.; Kitchen, J.A. Investigating the structure directing properties of designer 1,8-naphthalimide and amphiphilic sulfonate anions and their Fe $\mathrm{F}^{\mathrm{III}}$ thiosemicarbazone complexes. Cryst. Growth Des. 2017, 17, 5129-5144. [CrossRef]

66. Kitchen, J.A.; White, N.G.; Gandolfi, C.; Albrecht, M.; Jameson, G.N.L.; Tallon, J.L.; Brooker, S. Room-temperature spin crossover and Langmuir-Blodgett film formation of an Iron(II) triazole complex featuring a long alkyl chain substituent: The tail that wags the dog. Chem. Commun. 2010, 46, 6464-6466. [CrossRef] [PubMed]

67. Feltham, H.L.C.; Johnson, C.; Elliott, A.B.S.; Gordon, K.C.; Albrecht, M.; Brooker, S. "Tail” tuning of Iron(II) spin crossover temperature by $100 \mathrm{~K}$. Inorg. Chem. 2015, 54, 2902-2909. [CrossRef] [PubMed]

68. Soyer, H.; Dupart, E.; Gómez-García, C.J.; Mingotaud, C.; Delhaès, P. First magnetic observation of a spin crossover in a Langmuir-Blodgett film. Adv. Mater. 1999, 11, 382-384. [CrossRef]

69. Ketkaew, R.; Tantirungrotechai, Y.; Harding, P.; Chastanet, G.; Guionneau, P.; Marchivie, M.; Harding, D.J. OctaDist: A tool for calculating distortion parameters in spin crossover and coordination complexes. Dalton Trans. 2021, 50, 1086-1096. [CrossRef]

70. Barrett, S.A.; Halcrow, M.A. Anion-dependent spin crossover in solution for an Iron(II) complex of a $1 H$-pyrazolyl ligand. RSC Adv. 2014, 4, 11240-11243. [CrossRef]

71. De, S.; Tewary, S.; Garnier, D.; Li, Y.; Gontard, G.; Lisnard, L.; Flambard, A.; Breher, F.; Boillot, M.-L.; Rajaraman, G.; et al. Solution and solid-state study of the spin-crossover $\left[\mathrm{Fe}^{\mathrm{II}}(\mathrm{R}-\mathrm{bik})_{3}\right]\left(\mathrm{BF}_{4}\right)_{2}$ complexes $(\mathrm{R}=\mathrm{Me}$, Et, Vinyl). Eur. J. Inorg. Chem. 2018, 2018, 414-428. [CrossRef]

72. Chastanet, G.; Lorenc, M.; Bertoni, R.; Desplanches, C. Light-induced spin crossover-Solution and solid-state processes. Comptes Rendus Chim. 2018, 21, 1075-1094. [CrossRef]

73. Rodríguez-Jiménez, S.; Brooker, S. Solid versus solution spin crossover and the importance of the Fe-N $\equiv \mathrm{C}(X)$ angle. Inorg. Chem. 2017, 56, 13697-13708. [CrossRef] [PubMed]

74. Weber, B.; Walker, F.A. Solution NMR studies of Iron(II) spin-crossover complexes. Inorg. Chem. 2007, 46, 6794-6803. [CrossRef] [PubMed]

75. Forshaw, A.P.; Smith, J.M.; Ozarowski, A.; Krzystek, J.; Smirnov, D.; Zvyagin, S.A.; Harris, T.D.; Karunadasa, H.I.; Zadrozny, J.M.; Schnegg, A.; et al. Low-spin hexacoordinate Mn(III): Synthesis and spectroscopic investigation of homoleptic tris(pyrazolyl)borate and tris(carbene)borate complexes. Inorg. Chem. 2013, 52, 144-159. [CrossRef] [PubMed]

76. Martinho, P.N.; Gildea, B.; Harris, M.M.; Lemma, T.; Naik, A.D.; Müller-Bunz, H.; Keyes, T.E.; Garcia, Y.; Morgan, G.G Cooperative spin transition in a mononuclear Manganese(III) complex. Angew. Chem. Int. Ed. 2012, 51, 12597-12601. [CrossRef]

77. Clark, R.C.; Reid, J.S. The analytical calculation of absorption in multifaceted crystals. Acta Crystallogr. Sect. A Found. Crystallogr. 1995, 51, 887-897. [CrossRef]

78. Sheldrick, G. Crystal structure refinement with SHELXL. Acta Crystallogr. Sect. C Struct. Chem. 2015, 71, 3-8. [CrossRef] [PubMed] 